\title{
Present-Day Arctic Sea Ice Variability in the Coupled ECHAM5/MPI-OM Model
}

\author{
NikOLAY V. KOLDUNOV \\ Institut für Meereskunde, KlimaCampus, Universität Hamburg, and International Max-Planck Research \\ School on Earth System Modelling, Hamburg, Germany \\ DETLEF STAMMER \\ Institut für Meereskunde, KlimaCampus, Universität Hamburg, Hamburg, Germany
}

JOCHEM MAROTZKE

Max-Planck-Institute for Meteorology, Hamburg, Germany

(Manuscript received 2 February 2009, in final form 18 December 2009)

\begin{abstract}
As a contribution to a detailed evaluation of Intergovernmental Panel on Climate Change (IPCC)-type coupled climate models against observations, this study analyzes Arctic sea ice parameters simulated by the Max-Planck-Institute for Meteorology (MPI-M) fully coupled climate model ECHAM5/Max-PlanckInstitute for Meteorology Hamburg Primitive Equation Ocean Model (MPI-OM) for the period from 1980 to 1999 and compares them with observations collected during field programs and by satellites. Results of the coupled run forced by twentieth-century $\mathrm{CO}_{2}$ concentrations show significant discrepancies during summer months with respect to observations of the spatial distribution of the ice concentration and ice thickness. Equally important, the coupled run lacks interannual variability in all ice and Arctic Ocean parameters. Causes for such big discrepancies arise from errors in the ECHAM5/MPI-OM atmosphere and associated errors in surface forcing fields (especially wind stress). This includes mean bias pattern caused by an artificial circulation around the geometric North Pole in its atmosphere, as well as insufficient atmospheric variability in the ECHAM5/MPI-OM model, for example, associated with Arctic Oscillation/North Atlantic Oscillation (AO/ NAO). In contrast, the identical coupled ocean-ice model, when driven by NCEP-NCAR reanalysis fields, shows much increased skill in its ice and ocean circulation parameters. However, common to both model runs is too strong an ice export through the Fram Strait and a substantially biased heat content in the interior of the Arctic Ocean, both of which may affect sea ice budgets in centennial projections of the Arctic climate system.
\end{abstract}

\section{Introduction}

The projection of sea ice provided by the Intergovernmental Panel on Climate Change (IPCC) suggests a dramatic decline of Arctic summer sea ice extent (SIE) over the next 50 to 100 years. Yet, an analysis of the full ensemble of all IPCC climate projections of Arctic summer sea ice under increasing $\mathrm{CO}_{2}$ conditions shows a considerable spread of individual simulations (Stroeve et al. 2007 ) and reveals that only $50 \%$ of all solutions suggest an extinction of Arctic summer sea ice by 2100 (Serreze

\footnotetext{
Corresponding author address: Nikolay V. Koldunov, Institut für Meereskunde, KlimaCampus, Universität Hamburg, Grindelberg 5, 20144 Hamburg, Germany.

E-mail: nikolay.koldunov@zmaw.de
}

et al. 2007) in response to enhanced atmospheric $\mathrm{CO}_{2}$ concentrations. This points to substantial uncertainties in projected climate indices, among them summer sea ice parameters. At the same time it underlines the need to carefully test the skill of coupled climate models to improve them and to increase the confidence in the IPCC climate projections of important climate parameters.

With respect to testing sea ice simulations of models participating in the IPCC Fourth Assessment Report (AR4), several studies have been performed. For example, Parkinson et al. (2006) compared sea ice extent in 11 GCMs participating in IPCC AR4 [including the ECHAM/ Max-Planck-Institute for Meteorology Hamburg Primitive Equation Ocean Model (MPI-OM)] with satellite data. They found that, based on a subset of 11 models, on average they overestimated the mean sea ice extent in the 
Northern Hemisphere throughout the year with a maximum difference of $14.1 \%$ in concentration reached during September. Similar results were obtained by Zhang and Walsh (2006), Kattsov et al. (2007), and Arzel et al. (2006), who used different subsets of IPCC AR4 models. Hu et al. (2004) noted significant differences in multimodel annual mean ice thickness from IPCC AR4 models with the climatology of Bourke and Garrett (1987) in that the maximum ice thickness was shifted to the center of the Arctic Basin instead of north of Canadian Archipelago and toothick ice in the region from the Kara Sea to the Barents Sea. Gerdes and Köberle (2007) compared Arctic sea ice thickness variability in IPCC AR4 simulations of the twentieth-century climate and in ocean-sea ice hindcasts. The authors documented the significant spread in sea ice simulations and identified a few models with apparently better quality than others relative to observations. Most of the above studies agree that correct atmospheric forcing fields are critical for obtaining reasonable simulations of the sea ice characteristics (Walsh and Crane 1992; Bitz et al. 2002), more so than details of underlying sea ice models (Flato et al. 2004). Chapman and Walsh (2007) showed that, relative to the 40-yr European Centre for Medium-Range Weather Forecasts (ECMWF) ReAnalysis (ERA-40), IPCC AR4 models tend to have colder surface air temperatures $\left(\right.$ by $1^{\circ}-2^{\circ} \mathrm{C}$ ) and higher sea level pressure (SLP) over the Eurasian sector of the Arctic Ocean. Cassano et al. (2006) analyze Arctic circulation patterns in 10 IPCC AR4 models (excluding ECHAM5/MPI-OM) and found that high-pressure circulation patterns over the central Arctic are usually overestimated and that low-pressure patterns, such as the Icelandic low, are underestimated.

In contrast to previous ensemble investigations, the goal of this paper is to perform a detailed analysis of the MPI-M coupled ocean-ice model results. Specifically, the analysis aims at identifying the quality and potential causes of errors in the model's present day simulations of sea ice concentration and thickness distribution as well as ice transports. Testing the hindcast of coupled climate models against the existing climate data record provides a stringent test of the model's skill in simulating present-day climate and its variability. However, performing a detailed model evaluation against observations is difficult in a multimodel intercomparison context and usually takes an in-depth analysis of an individual simulation. The coupled ECHAM5/MPI-OM model was chosen here because it was identified before as one of the best in simulating sea ice parameters (Parkinson et al. 2006). Any deficit identified below is therefore likely to hold also for all other IPCC-type models.

The model evaluation will be performed based on two simulations of the identical ocean-ice coupled model.
One of the simulations is a twentieth-century simulation of the fully coupled ECHAM5/MPI-OM model. The second run is driven by the National Centers for Environmental Prediction (NCEP)/National Center for Atmospheric Research (NCAR) reanalysis. The two runs were identified because the first run represents a typical present-day climate simulation of an IPCC-type coupled model while the second run represents an ocean-sea ice simulation containing a more realistic atmosphere, thus quantifying in detail the impact of the atmosphere on the MPI-OM sea ice simulations. A comparison of model results will focus on the 20-yr period from 1980 to 1999 , which represents a typical sea ice "climatology" period that is used by most of the above-mentioned modelobservation comparison studies. We will see below that substantial problems exist with coupled climate models simulating the present day Arctic ice climate. We therefore left out the recent extreme years, which are being studied separately in several individual investigations (e.g., Kauker et al. 2009; Lindsay et al. 2009; Zhang et al. 2008).

The objectives of this study are in detail:

- to evaluate the skill of IPCC AR4 model ECHAM5/ MPI-OM in simulating climatological sea ice characteristics;

- to evaluate the skill of IPCC AR4 model ECHAM5/ MPI-OM in simulating Arctic climate variability;

- to estimate how atmospheric forcing influences sea ice characteristics in this specific model; and

- to estimate how different ocean states in the model may affect the simulated sea ice distribution.

The structure of the remaining paper is as follows: in section 2 we describe the approach and datasets used in this study as well as their uncertainties. In section 3 we discuss simulations of the sea ice concentrations and thickness and compare them with observations. Section 4 concentrates on ice transports. Section 5 describes atmospheric and ocean forcing fields. Section 6 provides a discussion and concluding remarks.

\section{Methodology}

Our study is based on output of the MPI-OM, which will be compared here with available satellite and in situ observations of sea ice concentration (SIC), sea ice thickness (SIT), and sea ice drift. In the following we will describe the underlying numerical experiments before summarizing the observations.

\section{a. MPI-OM model}

All numerical experiments are based on the coupled ocean-ice MPI-OM model. Technical details of the ocean module and the embedded sea ice module are provided 
by Marsland et al. (2003) and Jungclaus et al. (2006). The ocean model is based on the primitive equations for a hydrostatic Boussinesq fluid and is formulated with a free surface on an Arakawa $\mathrm{C}$ grid. It is run here with $1.5^{\circ}$ horizontal resolution and with 40 unevenly spaced vertical levels. The model uses an along-isopycnal diffusion following Redi (1982) and Griffies (1998), and isopycnal tracer mixing by unresolved eddies is parameterized following Gent et al. (1995). The embedded sea ice module is a Hibler-type dynamic-thermodynamic sea ice model with viscous-plastic rheology and snow (Hibler 1979). Thermodynamic growth of sea ice is described by the zero-layer formulation of Semtner (1976). The sea ice coverage is fractional within grid cells (frac) and related to the thickness according to subgrid-scale parameterization of lateral versus vertical ablation and accretion following Stössel and Owens (1992). Haak (2004) provided a detailed description of the ice model.

Jungclaus et al. (2006) investigated the general quality of the 300-year control integration of the ECHAM/ MPI-OM model and found that over much of the ocean sea surface temperature (SST) in the model deviated from the observations for less than $1 \mathrm{~K}$. But there is some greater regional difference, for example, the North Atlantic Current transports an excessive amount of heat to the Barents Sea region, leading to higher than observed SST there. Nevertheless global-scale transports of heat and freshwater are in the good agreement with observations, some temperature and salinity deviations from observations in intermediate and deep oceans are not large enough to seriously influence large-scale circulations and the North Atlantic overturning circulation is stable. The authors also made a rough examination of Arctic sea ice characteristics in the model and point to the lack of summer ice melting over Siberian and Canadian shelf and shifted sea ice circulation, issues that will be addressed here in detail.

The following two runs are analyzed during this study:

i) A twentieth-century ECHAM5/MPI-OM run with observed anthropogenic forcing $\left(\mathrm{CO}_{2}, \mathrm{CH}_{4}, \mathrm{~N}_{2} \mathrm{O}\right.$, CFCs, $\mathrm{O}_{3}$, and sulfate) which does not include any $\mathrm{CO}_{2}$ increase after the year 2000. In the following this run will be called ECHAM.

ii) A run of the MPI-OM model forced by the NCEPNCAR reanalysis (NCEP-RA1) surface forcing. In the following this run will be called FNCEP.

Because those two runs differ only in their atmospheric component and respective forcing fields, differences in the resulting sea ice characteristics and ocean conditions will shed light on the impact of the uncertainties of the atmosphere of the fully coupled climate model on the simulations of sea ice. We note that feedback processes over sea ice are included only in the ECHAM run. The NCEP atmosphere has feedbacks included to the extent that they are represented in observations that were assimilated, and since fluxes between the atmosphere and the ocean are calculated using the bulk formula, those feedbacks, at least to some extent, will be active here as well.

\section{1) THE ECHAM RUN}

The ECHAM5/MPI-OM model is a coupled oceanatmosphere-ice model, with the ocean-ice component represented by the MPI-OM model. For details of the ECHAM5 atmosphere model see Roeckner et al. (2003); it is based on version 5.2 of the ECHAM model and was run at a T63 spatial resolution, equivalent to a $1.875^{\circ}$ resolution in latitude and longitude, with 31 vertical levels. Atmosphere, ice, and ocean are coupled by means of the Ocean-Atmosphere-Sea Ice-Soil (OASIS) coupler (Valcke et al. 2003), which performs the interpolation between ocean and atmosphere grids. From the atmosphere to the ocean it transfers fluxes of momentum, heat and freshwater; from the ocean to the atmosphere it transfers sea surface temperature, sea ice thickness and concentration, snow thickness, and surface velocity. The coupled model includes a river runoff scheme (Hagemann and Dümenil 1997; Hagemann and Gates 2003) that treats river runoff and glacier calving interactively in the atmosphere model, and the respective freshwater fluxes are passed to the ocean as part of the atmospheric freshwater flux field.

For this study we use a simulation of the twentieth century driven by observed concentrations of climate relevant gases and aerosols $(20 \mathrm{C} 3 \mathrm{M})$. Three realizations of the twentieth century have been performed in this configuration, which started from three different initial conditions of a preindustrial control integration. However, instead of using an ensemble average of all three runs, we analyze only one individual run, following the recognition (e.g., Gerdes and Köberle 2007) that ensemble means contain less model-generated intrinsic variability than individual realizations which is the focus of this paper.

\section{2) THE NCEP FORCED RUN}

To investigate the sensitivity of the simulated SIE and the Arctic circulation and transport properties to the atmospheric forcing, we use the output available from a second experiment in which the ocean-ice component of the ECHAM/MPI-OM model was forced by the NCEP-RA1 reanalysis (Kalnay et al. 1996) with otherwise the same general setup, as described by Haak et al. (2003). The NCEP-RA1 forcing fields consist of a downward shortwave radiation, wind speed at $10 \mathrm{~m}$, total cloud 
cover, dewpoint temperature, precipitation, air temperature at $2 \mathrm{~m}$, wind stress, and mean river runoff. A global scaling factor of 0.89 was applied to the NCEP-RA1 downward shortwave radiation to correct for systematic bias between estimates of Earth Radiation and Budget Experiment (ERBE) and ECMWF (Haak et al. 2003). The model is initialized from Levitus et al. (1998) climatological temperature and salinity, and integrated 11 times (in a cyclic manner) using daily NCEP-RA1 reanalysis atmosphere forcing fields computed through bulk formulae for the time period 1948-2001, thus performing a 550year-long run. In ice-free regions, salinity in the surface layer $(0-12 \mathrm{~m})$ is restored toward the Levitus climatology, with a time constant of 180 days. Heat fluxes are parameterized through bulk formulae following Oberhuber (1993). As a consequence, the ocean's model upper-layer temperature or the sea ice/snow layer skin temperature reacts to changes in the air temperature very quickly. As in the case of ECHAM, we use also only a single run out of an ensemble of available FNCEP runs. Sea ice concentrations between FNCEP runs were compared previously by Haak (2004), who found that differences between runs are negligible (see, e.g., Fig. 6.2 of Haak 2004).

\section{b. Satellite observations}

Satellite data, used here for a test of the model results, were obtained from the National Snow and Ice Data Center (NSIDC) database and consist of sea ice concentrations inferred from Nimbus-7 Scanning Multichannel Microwave Radiometer (SMMR) and from channel 8, 11, and 13 radiance of the Special Sensor Microwave Imager (SSM/I) on board the Defense Meteorological Satellite Program (DMSP) at a grid cell size of $25 \times 25 \mathrm{~km}$ as described by Cavalieri et al. (1996). The SIC fields were generated from the measured radiances, using the National Aeronautics and Space Administration (NASA) Team (NT) algorithm developed by the Oceans and Ice Branch, Laboratory for Hydrospheric Processes at NASA Goddard Space Flight Center (GSFC).

In the following we will use satellite-derived SIC primarily from March and September, representing periods of highest and lowest sea ice concentration, respectively, and compare those with model results. Respective satellite fields are interpolated onto the ocean model grid by using distance-weighted averaging. In essence, the code searches for the four nearest neighbors of the destination grid point and calculates the mean of source grid points weighted by the distance from the destination grid point. Below we will refer to this dataset as "GSFC."
Figure 1 shows the time-mean GSFC SIC for March and September, both averaged over the period 1980 to 1999. While the March field reveals an entirely ice covered Arctic, the September field shows a substantially reduced ice cover around the rim of the basin, leaving maximum SIC to the north of Greenland. Shown in the lower row of the figure are associated standard deviation (STD) fields resulting for both months from monthly mean fields over the same 20 -yr period. We show STD values only in areas where time series of satellite SIC observations last more than 20 years, essentially covering the period after 1987 (leaving out some fraction of the central Arctic). The March fields show a fairly uniform ice distribution with close to $100 \%$ concentration over most of the Arctic. Noticeable interannual variability in March SIC exists only along the edges toward the Nordic Seas and in the Labrador Sea. We also note that the time mean and STD ice concentration fields hint at the impact of ocean transports on the ice edge and ice distribution, notably the ice concentration along the Greenland shelf and East Greenland Current as well as variations of the ice edge in the Barents Sea. During September, we find a variability around $10 \%$ of SIC over large parts of the central Arctic. However, a large interannual September SIC variability exists around the entire ice edge, especially on the Siberia shelf region.

In addition to satellite GSFC SIC fields, we use sea ice motion fields as provided by the Polar Pathfinder program on a daily basis and with a $25-\mathrm{km}$ spatial resolution (Fowler 2003). This dataset, covering the period from 1980 to 1999, was computed from Advanced Very High Resolution Radiometer (AVHRR), Scanning Multichannel Microwave Radiometer, Special Sensor Microwave Imager, and International Arctic Buoy Program (IABP) buoy data. Daily gridded fields combine data from all sensors.

While comparing models with satellite data, one needs to address also the observational uncertainties. A comparison with sea ice concentration fields obtained from AVHRR, Landsat, and Synthetic Aperture Radar (SAR) data (Comiso et al. 1997) showed that GSFC dataset tends to overestimate the sea ice concentration in regions with relatively low concentration (up to $+50 \%$ in some cases) and to underestimate this parameter in regions with relatively high ice concentration (up to $-20 \%$ in some cases). Moreover, Meier (2005) suggested that the NT algorithm underestimates ice concentrations (relative to AVHRR results) by $10.5 \%$ in summer and $8.4 \%$ during winter months. According to the data documentation in general, the accuracy of total sea ice concentrations is within $\pm 5 \%$ of the actual sea ice concentration in winter, and $\pm 15 \%$ in the Arctic during summer when melt ponds are present on the sea ice. Johnson et al. (2007) compared 

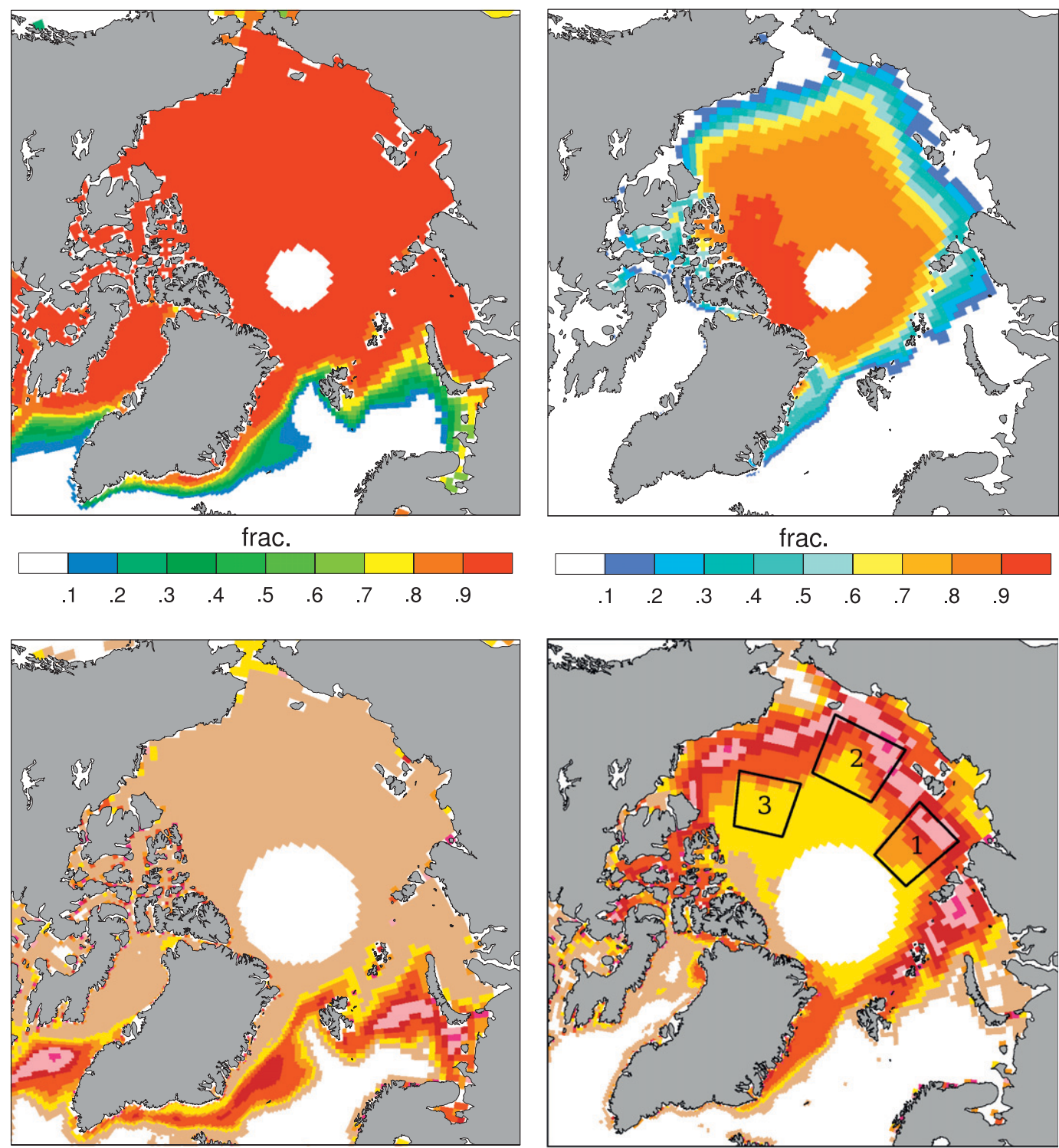

frac.
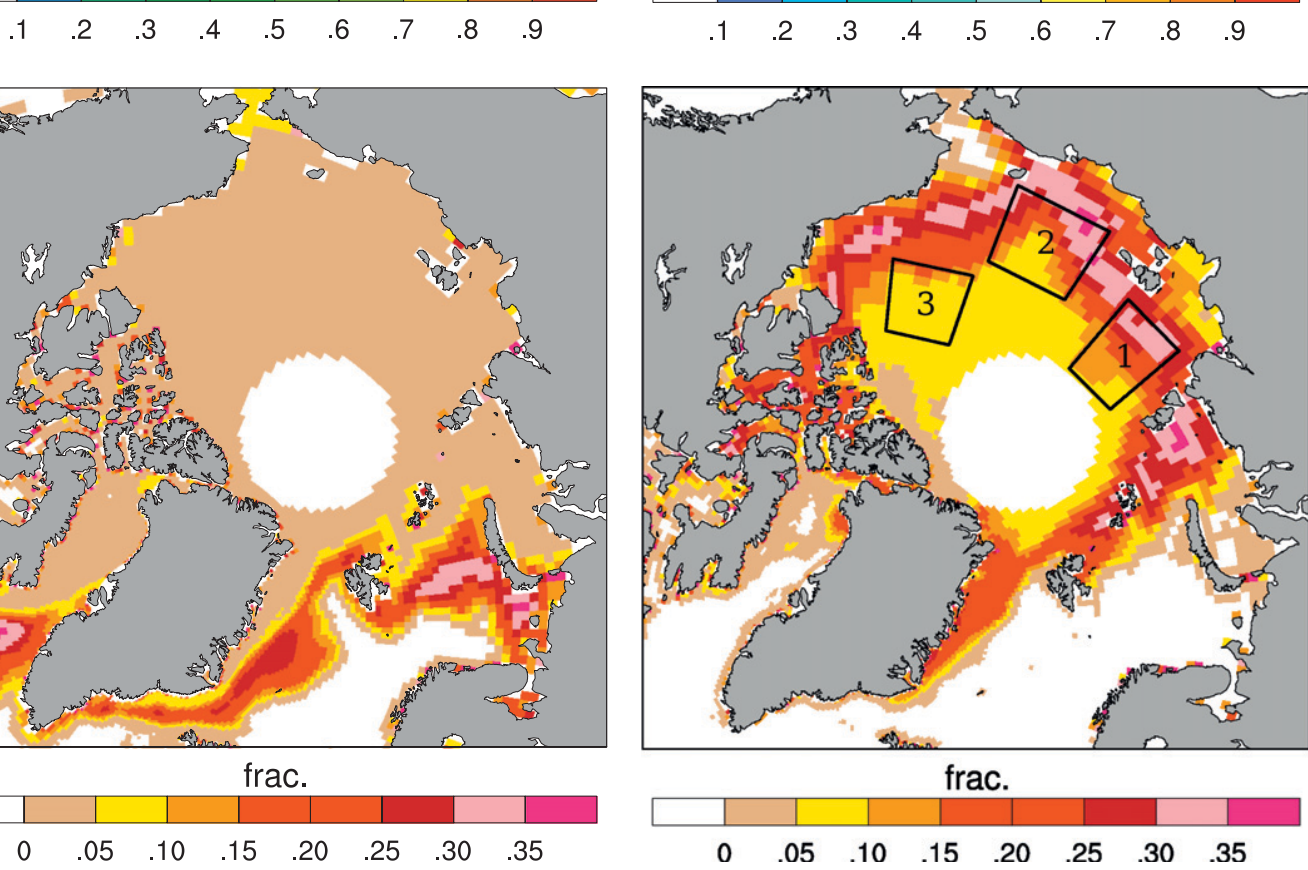

FIG. 1. (top) Mean sea ice concentration analyzed from the GSFC satellite data over the period 1980-99 for (left) March and (right) September. (bottom) Standard deviation of monthly mean sea ice concentrations analyzed from the GSFC satellite data over the period 1980-1999 for (left) March and (right) September. Rectangles indicate geographic locations for which time series of sea ice concentrations are shown in Fig. 9.

satellite-based observations of Arctic Ocean SIC with those simulated by nine models as part of the Arctic Ocean Model Intercomparison Project (AOMIP; Proshutinsky and Kowalik 2007). The authors showed that all models seem to agree reasonably well during winter months. During summer months, however, SIC estimates vary less between observational datasets than between models, suggesting a substantially larger uncertainty in summer sea ice simulations by climate models than uncertainties present in the observational database.

\section{c. In situ data}

Because of the lack of sea ice thickness observations, it is not straightforward to test the quality of sea ice thickness simulations of climate models. However, sea 
TABLE 1. Sea ice thickness (in m) for April and August-September. The label "Atlas" refers to Romanov (1995).

\begin{tabular}{|c|c|c|c|c|c|c|}
\hline \multirow[b]{2}{*}{ Location } & \multicolumn{3}{|c|}{ April } & \multicolumn{3}{|c|}{ August-September } \\
\hline & Atlas & ECHAM & NCEP & Atlas & ECHAM & NCEP \\
\hline Central Arctic & $2.4-3.2$ & $4-4.5$ & $2.8-4$ & $1.8-3$ & $3.5-4$ & $1.8-3.3$ \\
\hline Canadian Archipelago & 3.2 & $4-5$ & $4.5-5$ & $2.8-3$ & $4-5$ & $4-5$ \\
\hline Beaufort Sea & $2.4-3.2$ & 4.4 & $4-5$ & $1.2-2.4$ & $3.5-4$ & $3.2-4$ \\
\hline Coast of Alaska & $1.8-1.2$ & 4.5 & $3-4$ & $0-0.7$ & $0-3.2$ & $0-2.8$ \\
\hline Chukchi Sea & $1.8-1.2$ & $4.5-5$ & $3.8-4$ & $0-0.7$ & $0-3.2$ & $0-2.5$ \\
\hline East Siberian Sea & $1.8-2.4$ & $4.5-5$ & $3.5-4$ & $0.7-1.8$ & $3.2-3.8$ & $2-2.5$ \\
\hline Laptev Sea & $\leq 1.8$ & $3.2-3.8$ & $2.5-3$ & $0-1.2$ & $2.8-3.5$ & $1.2-2.4$ \\
\hline Kara Sea E & $1-1.7$ & $1.8-2.8$ & $1.5-2$ & $0-1.2$ & $0-1.8$ & 0 \\
\hline Kara Sea W & 1.3 & $1-2$ & $1-1.5$ & 0 & 0.7 & 0 \\
\hline
\end{tabular}

ice draft data collected by submarines in the Arctic Ocean represent a relatively extensive dataset in time and space from which ice thickness can be derived. Unfortunately, only respective data from the central Arctic Ocean have been unclassified by U.S. Navy and Royal Navy, while we find the highest model data discrepancies in the Siberian seas.

The sea ice morphometric collected during Soviet Union's "Sever" (Konstantinov and Grachev 2000) airborne expeditions and "North Pole" drifting station programs and other Russian sources were summarized by Romanov (1995) in the form of hand-drawn contour maps. The data in the Central Basin were obtained mostly in the 1970s, while the data in Siberian Shelf Seas have good spatial coverage also during the 1980s. Some of the data used for the creation of those maps are available at the NSIDC Web site (http://nsidc.org), where among other things, maps of spatial data distributions are available as well. We will use this data as SIT climatology. The other source of climatological thickness distribution is maps that cover the whole Arctic including marginal seas in Bourke and Garrett (1987). They used 17 submarine cruises during 1960-82 and some additional data to construct maps of seasonal thickness distribution. But unfortunately, in Bourke and Garrett (1987), no submarine measurements are available in Kara Sea and East Siberian Sea (cf. Table 1) and ice draft measurements from only two submarine cruises are available in the Northern Laptev Sea from 1960 and 1962.

We compare the maps from Romanov (1995) with the mean estimate of the ice draft field obtained from 25 years (1975-2000) of submarine ice draft observations in the central Arctic Ocean (Rothrock et al. 2008). The two datasets show good agreement in the Canadian and Alaskan sectors, but Romanov (1995) demonstrates lower values (up to $90 \mathrm{~cm}$ ) than Rothrock et al. (2008) in the area near the North Pole. The differences might be due either to climate variability, since the datasets cover two different periods, or to sampling problems in both datasets. Polyakov et al. (2003) estimated ice thickness of fast ice on the basis of Russian observations on coastal stations in four Arctic marginal seas from 1936 to 2000, and found that sea ice thickness trends are small (about $1 \mathrm{~cm} \mathrm{decade}{ }^{-1}$ ) and generally statistically insignificant. Also, maximum April-May fast-ice thickness measurements from Polyakov et al. (2003) and the map of sea ice thickness in April from Romanov (1995) show very good agreement. In summary, the comparison with Rothrock et al. (2008) and Polyakov et al. (2003) gives us a reason to assume that the maps of Romanov (1995) can be used as climatology for the $1980-99$ period.

\section{Sea ice concentration and thickness}

We will start the analysis of SIC by comparing simulated SIC fields with observations. The comparison will be performed in terms of seasonal and interannual SIC variations. The analysis of sea ice transports, of differences in the atmospheric forcing and in the underlying ocean simulations will follow in the next sections.

\section{a. Seasonal distribution of sea ice concentration}

Figure 2 shows that simulated SIC from the model runs ECHAM and FNCEP for March are in good agreement with satellite data (cf. Fig. 1). In both cases the fields show concentrations near unity, and the locations of the ice edge agree with observations almost everywhere. The largest discrepancy appears in the reproduction of the ice tongue along the Greenland shelf, associated with the East Odden, where the model realizations tend to overestimate the observed SIC in this region. The ECHAM run shows somewhat better results than FNCEP near Greenland, but underestimates SIC in the region between Spitsbergen and Novaya Zemlya islands. In contrast, FNCEP simulates too much ice near Greenland and closer to observations in the region between Spitsbergen and Novaya Zemlya islands. Nevertheless, we can conclude that the model runs satisfactorily reproduce the wintertime sea ice extent and concentration. 


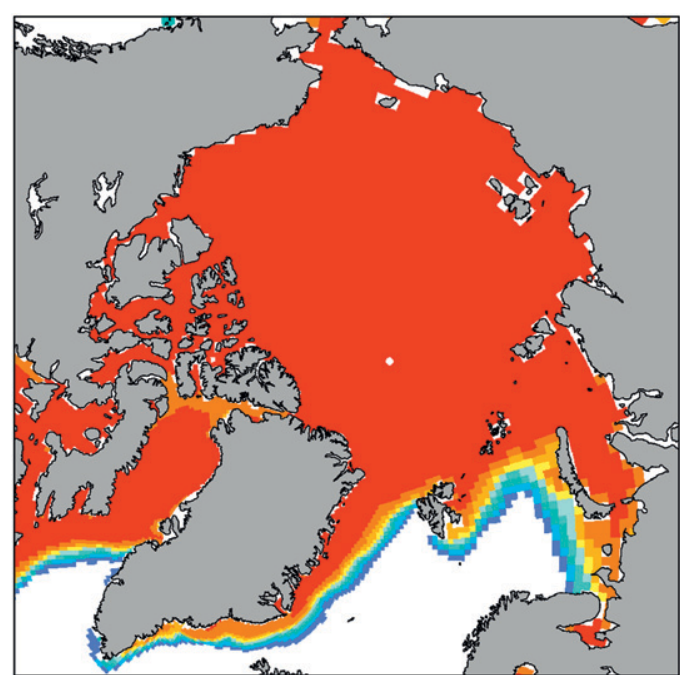

frac.
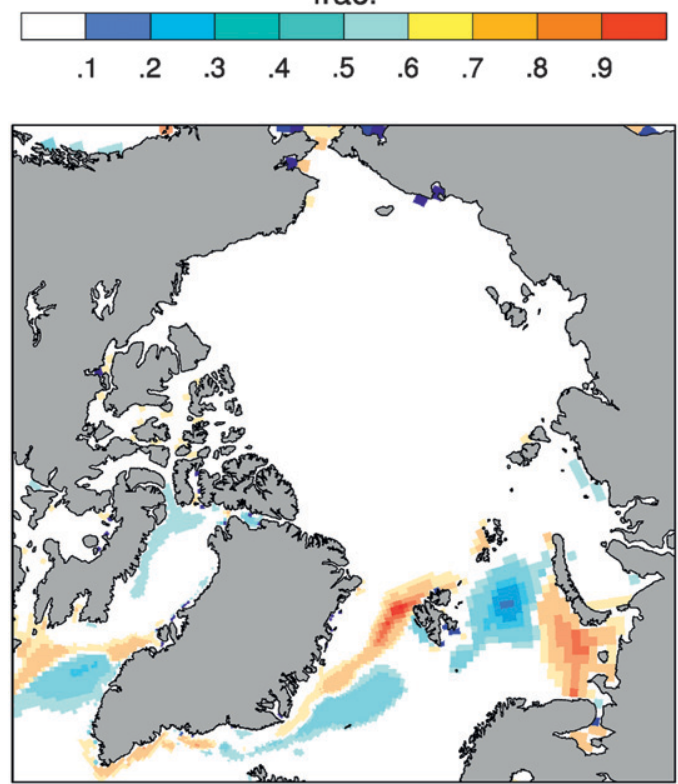

frac.

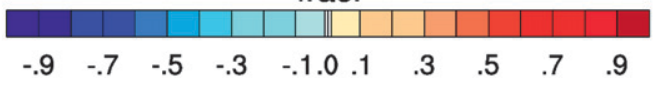

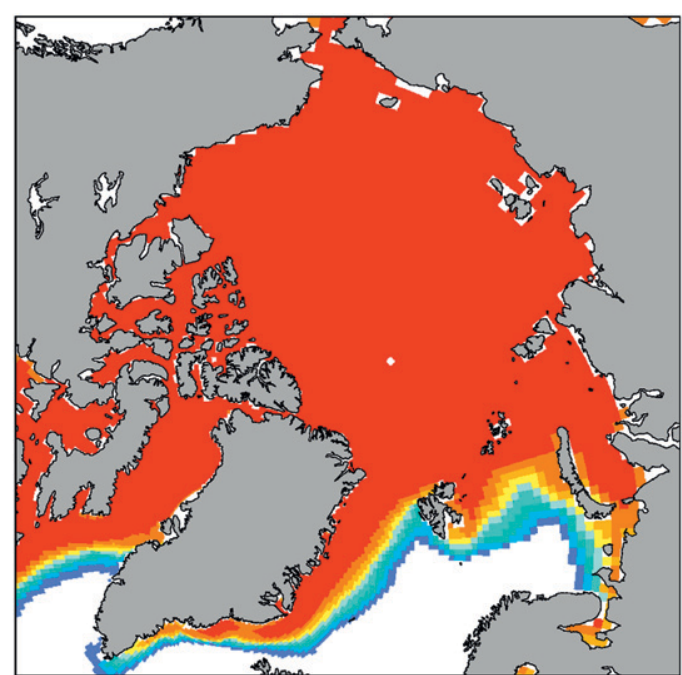

frac.

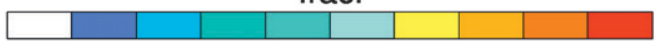

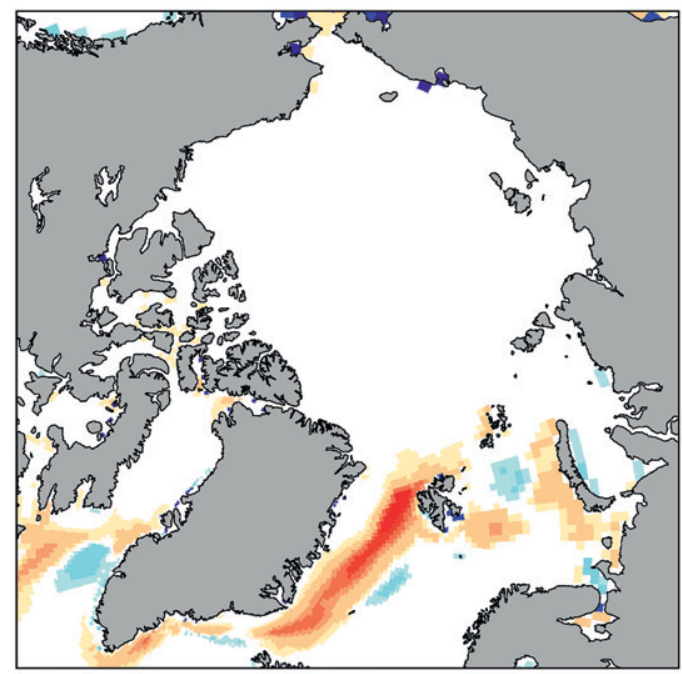

frac.

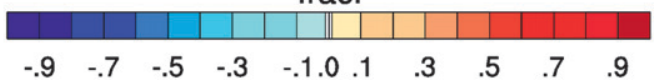

FIG. 2. (top) March mean sea ice concentrations (1980-99) simulated by (left) the ECHAM run and (right) the FNCEP run. (bottom) Differences in March mean (1980-99) sea ice concentrations of (left) ECHAM minus GSFC and (right) FNCEP minus GSFC.

The situation is substantially different during September (Fig. 3) when the simulated sea ice concentrations show significant discrepancies with respect to observations, even after taking into account errors in satellite data. Most noticeable, both model runs overestimate SIC in the Laptev and East Siberian seas, near the Canadian coast and in the Canadian Archipelago. Positive biases reach concentration values of $0.4-0.6$ in the Canadian Archipelago and 0.8 along the east Siberian coast. Satellite data suggest that the latter region is ice free during summer months, or at least has low ice concentration, while both models show high SIC for this region. This holds especially for the ECHAM run, which shows further positive biases near Spitsbergen, Franz Josef Land, and east of Greenland. In contrast, negative biases of about 0.4-0.5 are present in the FNCEP run to the north of the Kara Sea and further to the center of the Arctic Basin.

By showing the summer sea ice extent between 1900 and 2008 as simulated for twentieth-century conditions 


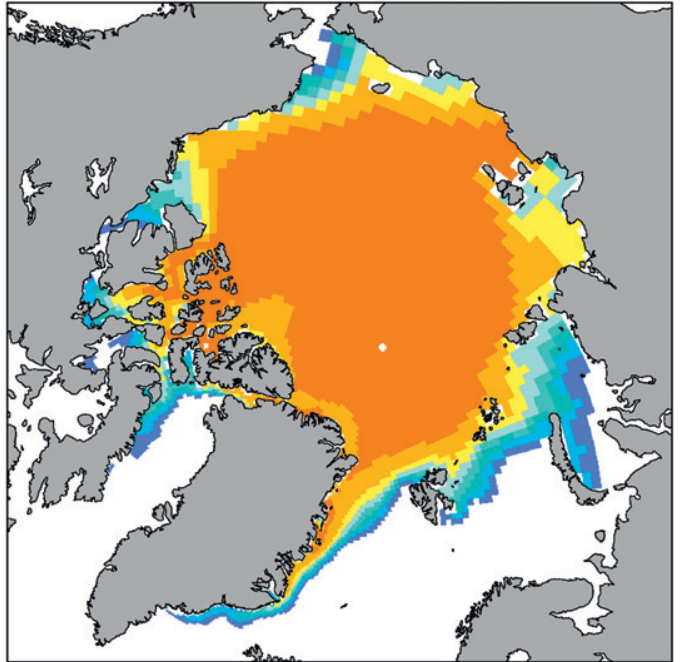

frac.

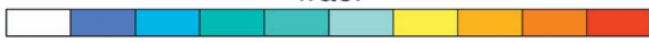

$\begin{array}{lllllllll}.1 & .2 & .3 & .4 & .5 & .6 & .7 & .8 & .9\end{array}$

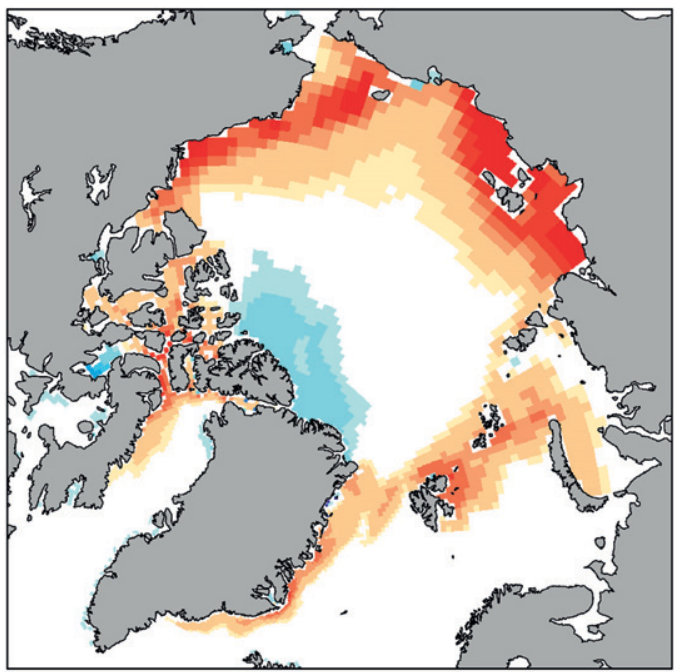

frac.

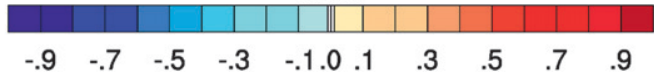

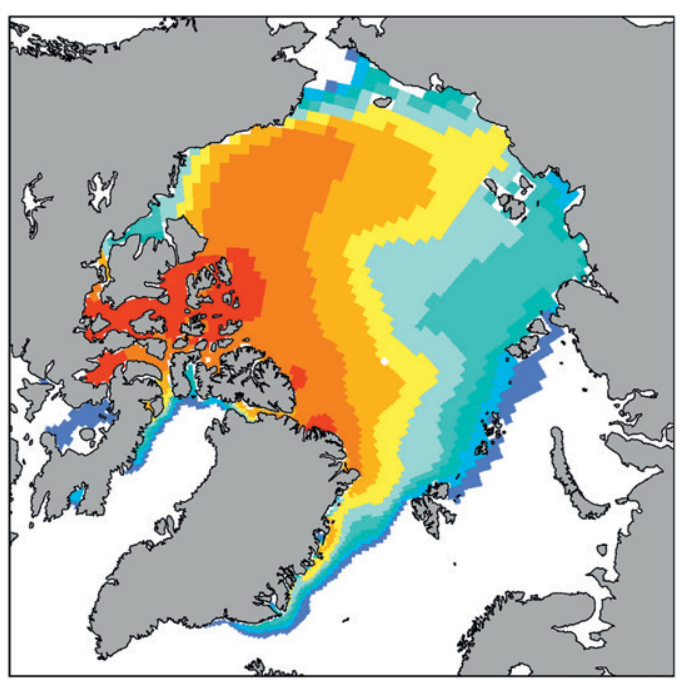

frac.

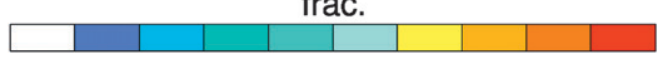

$\begin{array}{lllllllll}.1 & .2 & .3 & .4 & .5 & .6 & .7 & .8 & .9\end{array}$

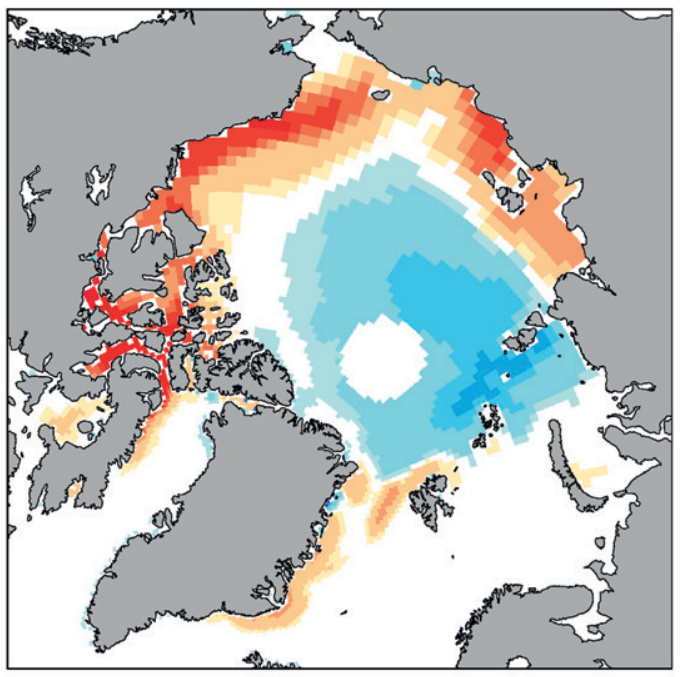

frac.

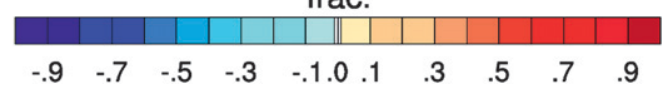

FIG. 3. As in Fig. 2, but for September.

by the ECHAM and FNCEP runs together with the observed Arctic summer sea ice extent for the satellite era, Fig. 4 illustrates the (by now well known) decline of the summer SIC over the entire observational record (see also the recent discussion by Parkinson and Cavalieri 2008). SIC also declines in the twentieth-century ECHAM run, but more slowly than observed. In contrast, the FNCEP run visually comes much closer to observed sea ice conditions in terms of the general level of SIE, and its decline rate, but also in terms of its interannual variability; however, the decline rate does not withstand a formal significance test. A comparison of the ECHAM and FNCEP results suggests a large sensitivity of the detailed characteristics of sea ice simulations to the details of the atmospheric forcing. Anticipating results, which are presented below, Fig. 4 thus already suggests that much of the deficits in the sea ice simulation of the coupled ECHAM model arise to a large extent (and maybe more than anything else) from problems in the model's atmosphere. This is consistent with results of previous studies, based on the earlier generations of climate models (Walsh and Crane 1992; Bitz et al. 2002; 

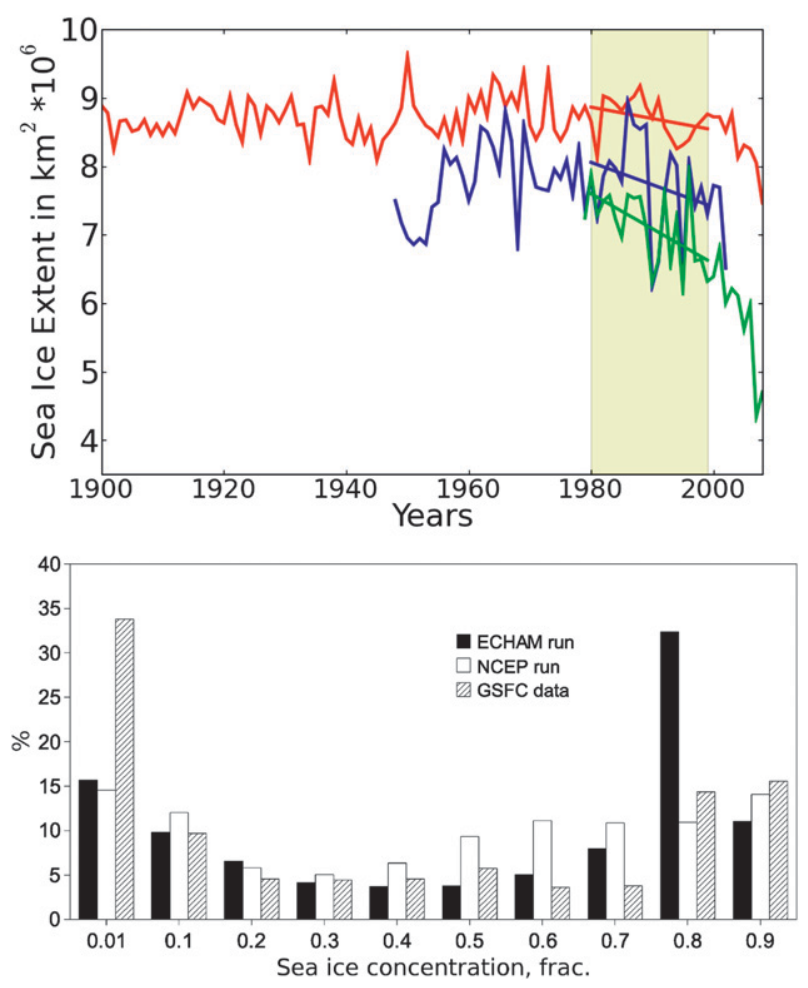

FIG. 4. (top) September Arctic Sea ice extent $\left(\mathrm{km}^{2} \times 10^{6}\right)$ as observed over the last $30 \mathrm{yr}$ (through 2008; green curve) and as simulated by the MPI-OM ECHAM run (red curve), and the FNCEP run (blue curve). The period used in this analysis is marked by the rectangle, and the linear least squares fit through this period is shown by straight lines. (bottom) Distribution of Northern Hemisphere sea ice concentration (bin width 0.1 frac, beginning at 0.01 frac.) for September (1980-99), as simulated by the two model runs and as observed by satellites.

Flato et al. 2004) and there is not much improvement to report in this respect (Chapman and Walsh 2007). Eisenman et al. (2007) discussed recently the impact of errors in the cloudiness over the Arctic on equilibrium sea ice solutions.

Figure 4 in its lower panel shows histograms of September SIC as they follow from GSFC data and from the two model runs. In the case of GSFC, the distribution peaks near concentrations of zero and unity, and thus has a shape not unlike that of the probability distribution of a harmonic function. The most significant differences to this observed distribution appears to exist in the ECHAM run, which peaks around unity, suggesting that the simulation of summer sea ice by this model is by far too compact as compared to observations, but also as compared to the FNCEP run. In contrast, histograms from all three datasets agree for March (not shown), again suggesting that the biggest problems exist in the summer sea ice concentrations of the ECHAM climate model. Our findings are in agreement with conclusions drawn by Deweaver and Bitz (2006), who identified the absence of typical atmospheric summertime features in the atmospheric circulation to be a primary problem of the NCAR Community Climate System Model 3.0 (CCSM3) sea ice simulation. The consistency of both conclusions might indicate that this is a more general problem in climate models.

\section{b. Seasonal sea ice thickness}

In Figs. 5 and 6 we compare simulated and observed SIT fields. For that purpose climatological SIT maps were adapted from Romanov (1995) for April and AugustSeptember (a March SIT climatology was not available). During April (Fig. 5), the climatological SIT is continuously decreasing in space from the north of Greenland and the Canadian Archipelago toward the Siberian Shelf seas and the coast of Alaska. Compared to Romanov (1995), the SIT in the ECHAM run is by far too thick (with a mean values of 4-5 m) in the central Arctic Ocean, north of Greenland, off the Canadian coast, and in the Chukchi and East Siberian seas. There are two areas where SIT maxima of $5 \mathrm{~m}$ are reached in ECHAM, one to the north of Greenland and another near the coast of the East Siberian Sea. Nevertheless, the ECHAMsimulated SIT continuously decreases toward the western part of the Arctic. For FNCEP, SIT is reduced overall relative to the ECHAM run but still exceeds the values from Romanov (1995). Thick sea ice (3-4 m) occupies the center of the Arctic Ocean, the coast of Alaska, and the Chukchi and East Siberian seas. There is only one SIT maximum to the north of Greenland, but ice accumulated near the East Siberian and Chukchi seas coast is thicker than in the areas offshore. Continuous decrease of SIT toward the western part of the Arctic is also present but starts much closer to the center of the Arctic Ocean than in ECHAM and Romanov (1995).

The observed SIT distribution in August-September (Fig. 6) is characterized by a maximum (about $3 \mathrm{~m}$ ) in the Canadian basin with SIT values declining below $70 \mathrm{~cm}$ toward the Siberian Shelf and toward zero in the Kara Sea. In contrast, the SIT maximum in the ECHAM run is shifted laterally toward the North Pole, and from there SIT decreases steadily toward the Beaufort Sea, the coast of Alaska and the Chukchi Sea on one side, and the Laptev, Kara, and Barents seas on the other side. Sea ice thicker than observed is simulated in the East Siberian Sea (especially the western part), the Canadian Archipelago and Greenland, where the sea ice reaches its thickness maximum. In the FNCEP run, maximum SIT is located near the Canadian Archipelago, with a tongue of thick ice shifted to the Beaufort Sea and coast of Alaska, and further propagates toward the East Siberian Sea. As in winter, SIT is overestimated also 

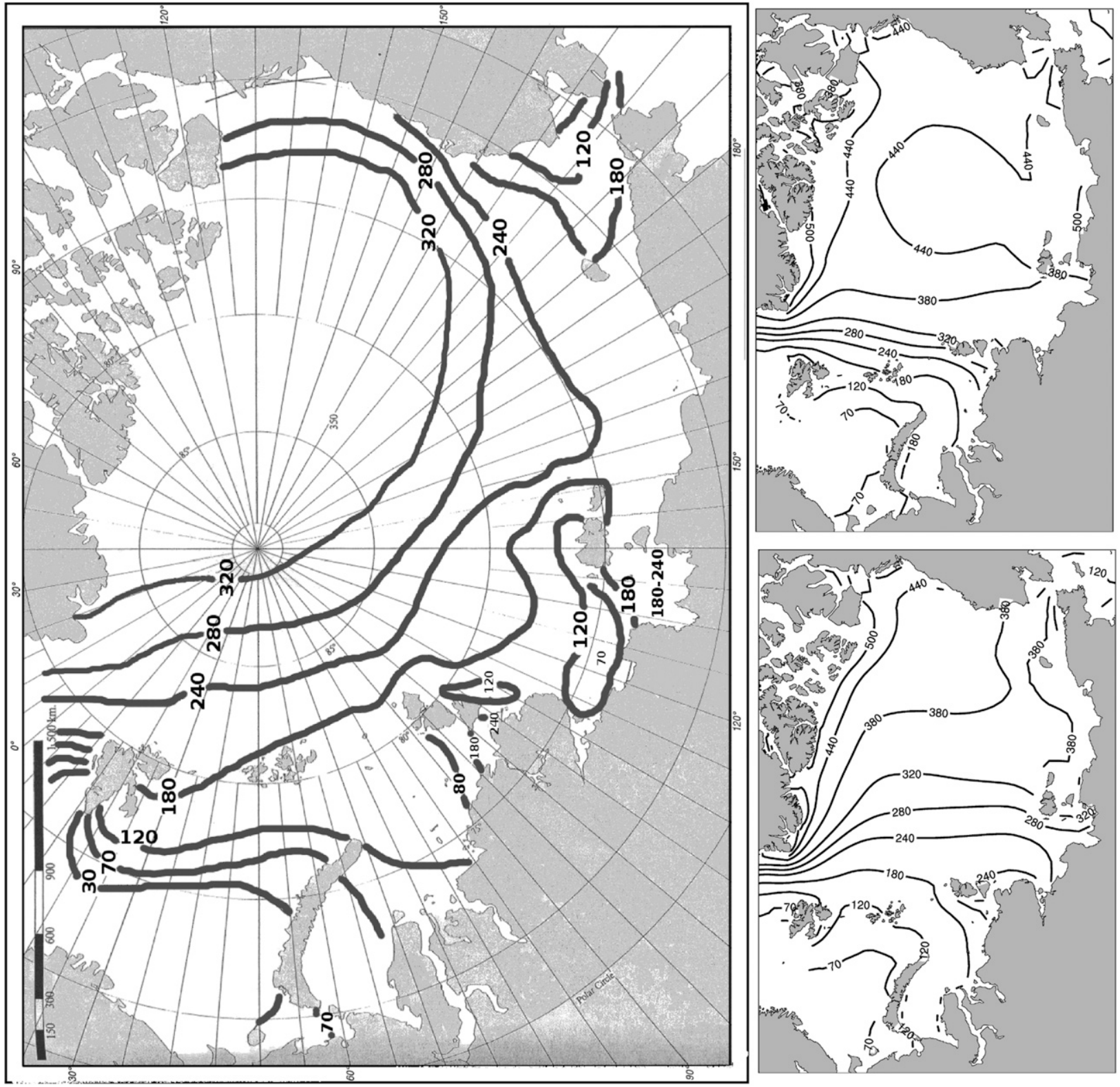

FIG. 5. (left) Climatological April mean thickness (in cm) of observed sea ice, adapted from Romanov (1995). (right) Mean April sea ice thickness for (top) ECHAM and (bottom) FNCEP.

during summer months by both model runs. Potentially more troublesome might be the fact that the model simulates the wrong spatial structures of the summer sea ice thickness.

The above-mentioned SIT values are summarized in Table 1 for April and for September. From the table it is obvious that the spatial distribution of SIT is not well represented in the models, but also that differences between model runs are significant. While the FNCEP run tends to be closer to the climatological numbers, one has to be careful in this comparison, in that the climatological thickness distributions are also very uncertain (much more so than previously discussed satellite SIC observations).

A summary of simulated SIT is provided in Fig. 7 in form of a histogram of SIT simulated in the ECHAM and FNCEP runs (because observations are present only in form of hand-drawn maps, it is impossible to include them into the figure): both model runs show roughly the same bimodal distribution during March; however, during September, the ECHAM run shows a peak in the distribution for 4-m thick sea ice, which is absent in the FNCEP run. Not only does the ECHAM run simulates too compact ice 

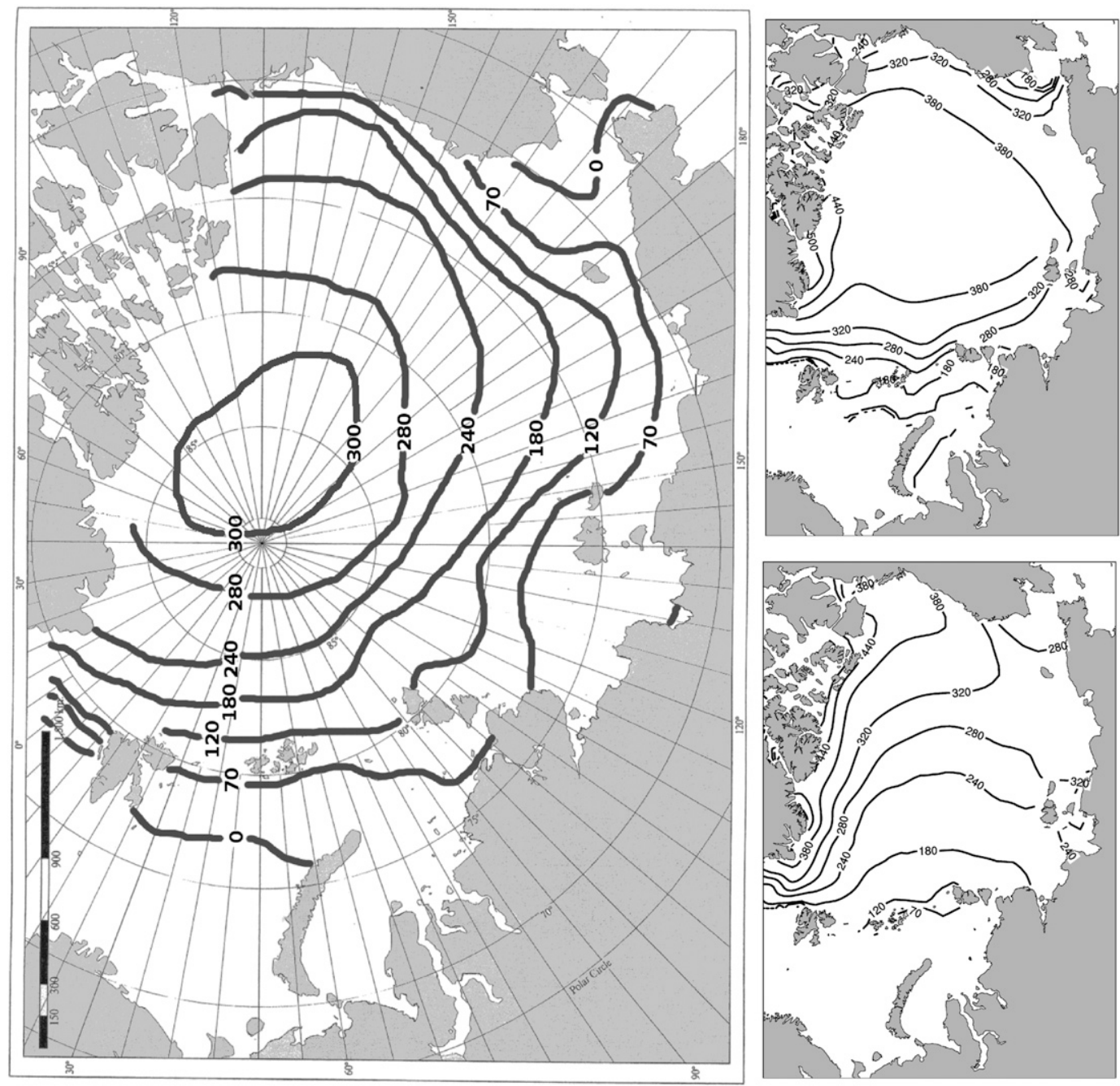

FIG. 6. As in Fig. 5, but for August-September.

(cf. Fig. 4), it actually also produces too thick summer ice as compared to the FNCEP run and presumably also as compared to the few available observations.

\section{c. Interannual variations of sea ice concentration}

Fields of the STD of observed SIC (Fig. 1, lower panels) suggest a substantial interannual variability in September SIC over the continental slope and shelf areas of the Eurasian sector. For comparison, Fig. 8 shows the respective fields of September SIC, but now from the ECHAM and FNCEP runs. The figure reveals that significant variability in SIC occurs only at the ice edges of the ECHAM run, notably on the Siberian shelf and toward the Barents Sea. However, hardly any variability in the simulated sea ice is present in the central Arctic. In contrast, observations indicate a further retreat of summer sea ice and much more variability in the central Arctic. We note that, unlike ECHAM, the FNCEP run shows a high degree of interannual SIC variability over a large fraction of the Siberian sector of the Arctic and to the east of the Lomonosov Ridge.

For a quantitative comparison of the model's interannual SIC variability with observations, we show in Fig. 9 time series of observed and simulated monthly mean September SIC from three representative areas (see Figs. 1 and 8 for the geographic positions of these areas). It is obvious that the ECHAM run shows very little interannual variability, while the FNCEP run matches better the observed interannual variability, albeit often with different amplitude. The top panel represents a region in the northern part of the Laptev Sea, where observations and the FNCEP run suggest high interannual September SIC variability. ECHAM time series show a lower STD and higher mean concentration of September SIC. In the FNCEP run, because this geographic location is very close to its sea ice edge, 

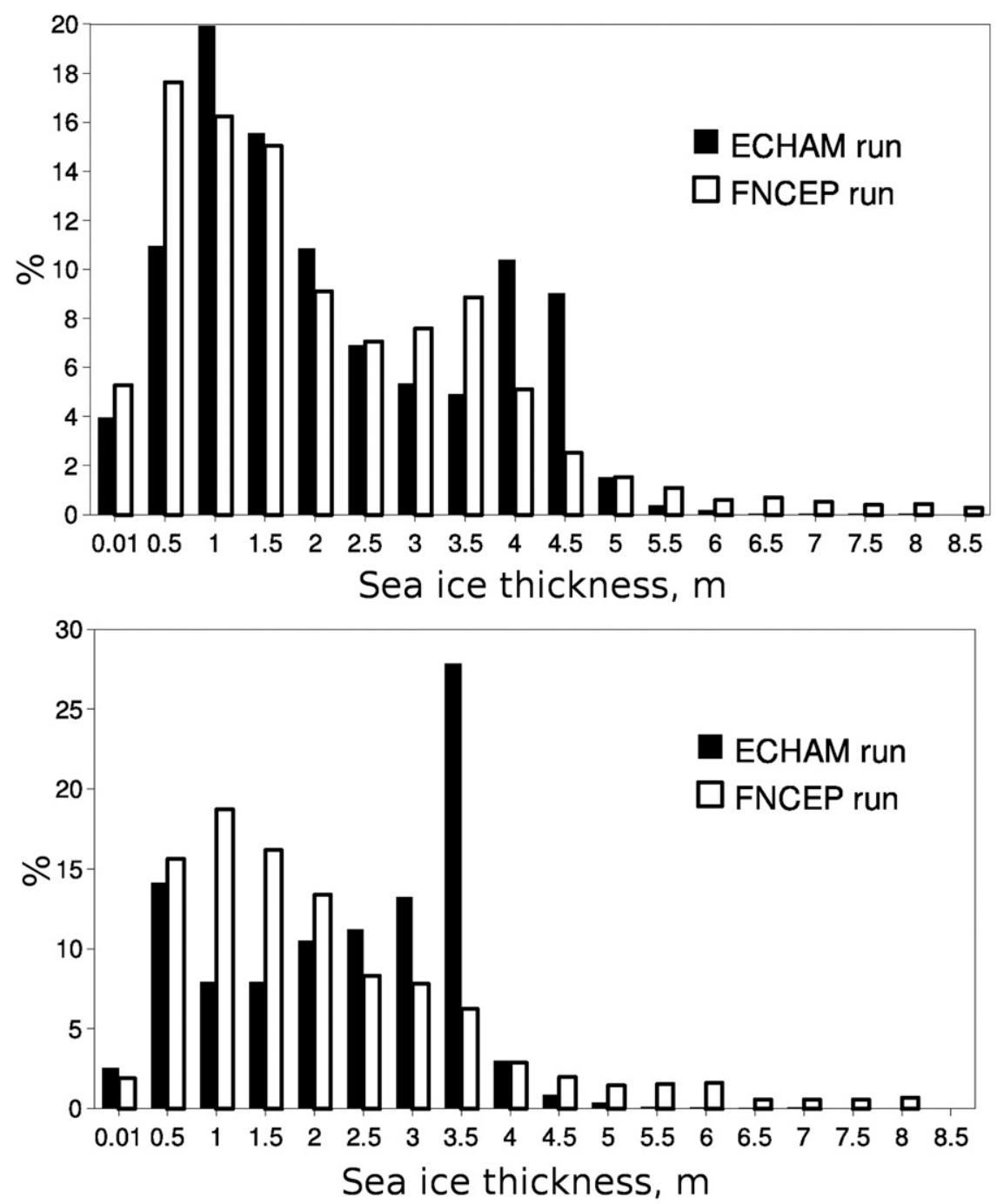

FIG. 7. Distribution of sea ice thickness in (top) March and (bottom) September (bin width $0.5 \mathrm{~m}$, beginning at $0.01 \mathrm{~m}$ ) as simulated by the ECHAM and FNCEP model runs.

a stronger interannual variability can be found; nevertheless, the generally better agreement between FNCEP and GSFC is still apparent.

The middle panel represents SIC variations in the area north of the East Siberian Sea, which includes the ice edge in the GSFC data as well as central parts of the Arctic Ocean. Despite the fact that the spatial distribution of STD fields in the FNCEP and GSFC fields are different, mean values are close to each other. The ECHAM run again does not simulate enough interannual variability since its ice edge is very close to the coast in this region. The bottom panel represents a location at the center of the Arctic Basin, where satellite data show high September SIC concentrations and low interannual variability. Here both model runs agree with observations. Common to all three panels of Fig. 9 is that the FNCEP run tends to produce more realistic results and that the error in the coupled ECHAM run is considerably larger.

We calculate NAO indexes for the ECHAM and NCEP runs (not shown) and find that the NAO standard deviation in ECHAM run is smaller by a factor of 1.7 than the NAO standard deviation in the FNCEP run. Lack of interannual variability suggests that our coupled model does not represent realistically some fundamental characteristics of atmospheric variability over the Arctic (see, e.g., the analysis of NAO representation in ECHAM5 by Pinto et al. 2008).

\section{Sea ice transports}

Sea ice drift is an important parameter determining the distribution and thickness of sea ice in the Arctic 

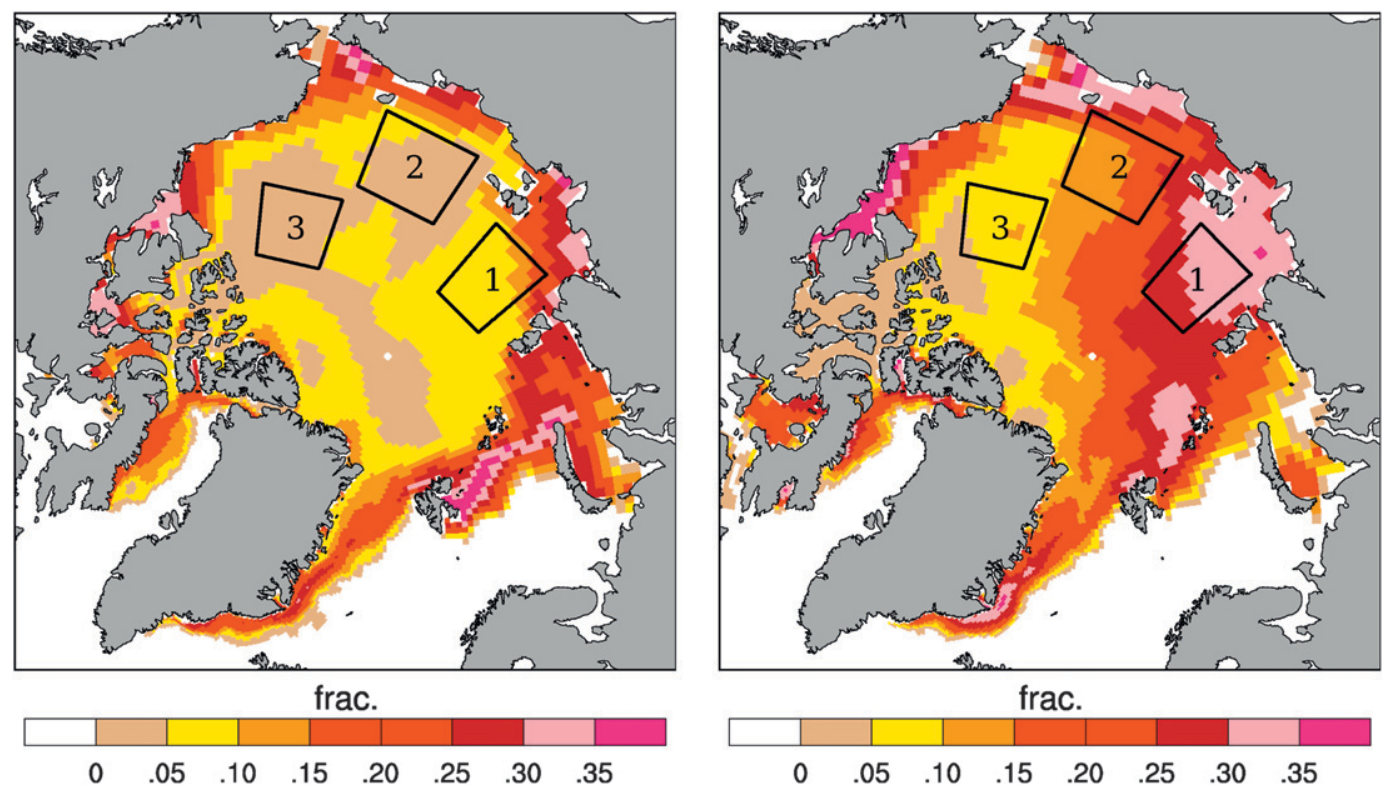

FIG. 8. Standard deviation of monthly mean sea ice concentrations for September (1980-99) (left) in the ECHAM run and (right) in the FNCEP run. Rectangles indicate geographic locations for which time series of sea ice concentrations are shown in Fig. 9.

Ocean, as well as the sea ice export into the Nordic seas. Observations of sea ice drift are available from the Pathfinder dataset on a 25-km spatial grid (Fowler 2003). Monthly mean sea ice velocity vectors, representing the years 1980-99, are shown in Fig. 10 for March and October. October is shown here instead of September because of problems with passive microwave radiometer observations of sea ice drifts during September (Kwok et al. 1998; Maslanik et al. 1996).

Observed March ice transports display two main sea ice drift features, notably the Beaufort gyre located in the Canadian Arctic Ocean, and a transpolar drift. In the Beaufort gyre, ice is transported anticyclonically, bringing ice from the Canadian shelf to the north of Alaska and the Chukchi Sea. The opposite side of the Beaufort gyre is part of the transpolar drift, feeding ice from the Siberian shelf region all the way toward the Fram Strait where it is exported into the Nordic seas. The transpolar drift originates from the Laptev and the East Siberian seas. Another, yet smaller, feature in ice transport is the Barents Sea transport, which also feeds sea ice toward the Nordic seas. As compared to March, October observations show essentially similar, but enhanced, transport structures, with a stronger and larger Beaufort gyre and a stronger transpolar drift.

In the ECHAM run the center of the Beaufort gyre is shifted, forming a strong anticyclonic ice gyre in the central Arctic Ocean, and the transpolar drift is shifted toward Severnaya Zemlya Islands and Franz Josef Land; that is, more toward the sea ice edge. As a consequence, the ice export from the East Siberian Sea is very small in the ECHAM run and a transpolar drift is quasi absent. Ice exported through the Fram Strait originates mainly from the area of the Eurasian shelf break. We note also that due to the strong Arctic ice gyre, the ice on the Siberian shelf originates to some extent from the $\mathrm{Ca}$ nadian part.

We conclude from Fig. 10 that the observed ice transport is very poorly represented in the ECHAM run. This problem seems much remedied in the FNCEP run (bottom row of Fig. 10), pointing again toward the atmosphere as the primary cause for uncertainties in high-latitude climate parameters in the coupled ECHAM model. In the FNCEP run, the center of the Beaufort gyre and the transpolar drift is now much more realistic both in terms of structure and amplitude. However, the main source of the ice exported southward through Fram Strait is not the central Arctic Ocean, but the area to the north of Greenland.

Figure 10 already indicates that the southward sea ice transport through the Fram Strait (and Davis Strait) in both model runs is much larger than what is observed. This is quantified in Fig. 11 showing a histogram of sea ice velocity magnitude for the entire Northern Hemisphere. For the comparison, observed ice velocities from Pathfinder data were interpolated to the model grid, and simulated ice velocities are used only over regions with SIC exceeding 0.15. During March, the maximum percentages in all three time series are between 0.01 and $0.03 \mathrm{~m} \mathrm{~s}^{-1}$, albeit at different levels: The Pathfinder data 

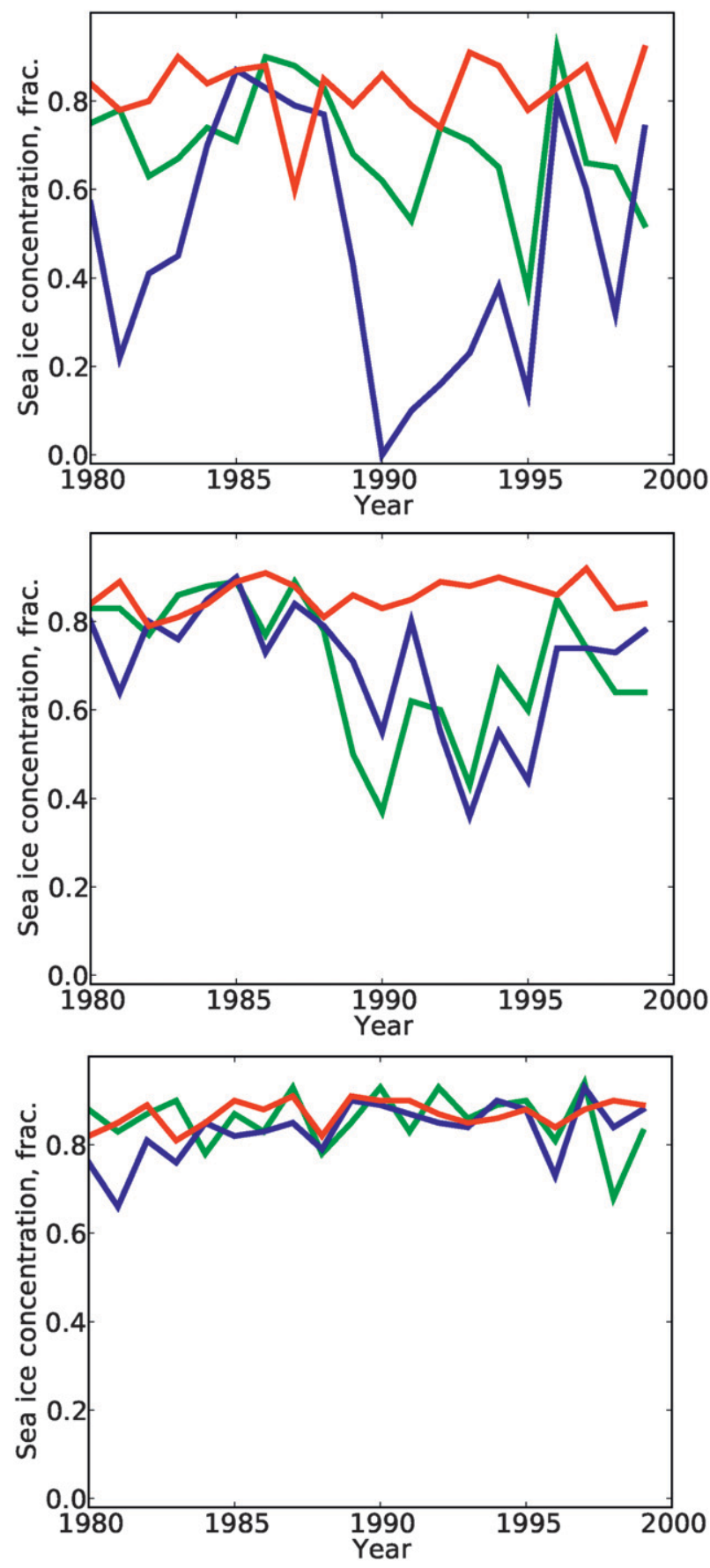

FIG. 9. Time series of mean September sea ice concentrations from different areas for the period 1980-99. Shown are GSFC observations (green curve), the ECHAM run (red curve), and the FNCEP run (blue curve). Time series from positions (top) 1, (middle) 2, and (bottom) 3 in Figs. 1 and 8.

peak at a $19 \%$ level near $0.02 \mathrm{~m} \mathrm{~s}^{-1}$ velocity magnitude, the ECHAM and FNCEP data peak at $9 \%$ and $13 \%$, respectively, near the same velocity magnitude. In Pathfinder, data percentages decline rapidly for velocity magnitudes $>0.1 \mathrm{~m} \mathrm{~s}^{-1}$, while in the ECHAM and
FNCEP runs they decline more slowly, reaching values of $0.4 \mathrm{~m} \mathrm{~s}^{-1}$ and are more associated with the ice export through the Fram Strait. In September, peaks of the ice velocity magnitude distribution in the ECHAM and FNCEP runs are shifted relative to the Pathfinder data toward higher values, but overall sea ice transports are smaller. We note that the shape of the FNCEP distribution agrees more with the Pathfinder data than with the ECHAM result especially in March. Martin and Gerdes (2007) compare AOMIP model's simulations of the ice transport with satellite observations and also found that AOMIP models tend to have a lesser percentage of low velocity magnitude and a higher percentage of high velocity amplitudes.

Only a few observation-based estimates of ice volume transports through the Fram Strait are available for a comparison (Kwok et al. 2004; Vinje et al. 1998). As expected, the model ice volume export through Fram Strait is higher than observational estimates (Fig. 12). In addition, the 1980-99 time-mean FNCEP transport (3997 $\mathrm{km}^{3} \mathrm{yr}^{-1}$ ) is higher than the ECHAM time-mean transport $\left(3467 \mathrm{~km}^{3} \mathrm{yr}^{-1}\right)$, which can be rationalized by the fact that differences exist in the sea ice pathways feeding ice with different thicknesses toward the Fram Strait: in the ECHAM run the sea ice drifts to the Fram Strait mainly from the Eurasian part of the Arctic Ocean; this ice is relatively young and thin. In the FNCEP run the main source for the sea ice in the Fram Strait lies to the north of Greenland, where thick, multiyear ice is situated.

\section{Forcing fields}

Based on the differences between the sea ice simulations obtained from the coupled ECHAM and the FNCEP runs, we hypothesized above that these differences emerge primarily from differences between the ECHAM atmosphere and the NCEP-RA1 reanalysis in terms of surface flux fields. However, differences in the atmosphere forcing fields also lead to different Arctic Ocean properties that may affect sea ice from below. In the following, we will quantify the impact of atmospheric and ocean forcing on sea ice properties by analyzing differences in the fields of air temperature at 2-m height (SAT), sea level pressure (SLP), and ocean hydrographic properties from both runs.

\section{a. Atmospheric forcing}

With respect to March SAT, Fig. 13 reveals that the field is biased high in the ECHAM run by $0.7^{\circ} \mathrm{C}$ (averaged over the Arctic Ocean north of $60^{\circ} \mathrm{N}$ ) relative to the NCEP-RA1 reanalysis. Nevertheless spatial structures agree in that SAT increases in both fields from the 


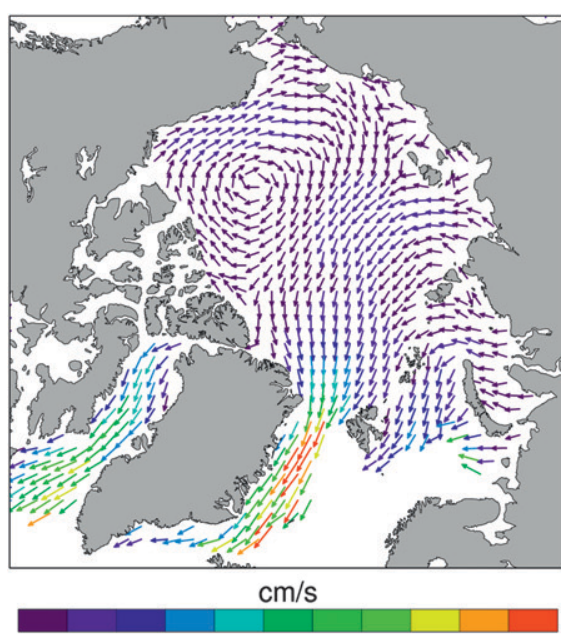

$\begin{array}{llllllllll}1 & 2 & 3 & 4 & 5 & 6 & 7 & 8 & 9 & 10\end{array}$

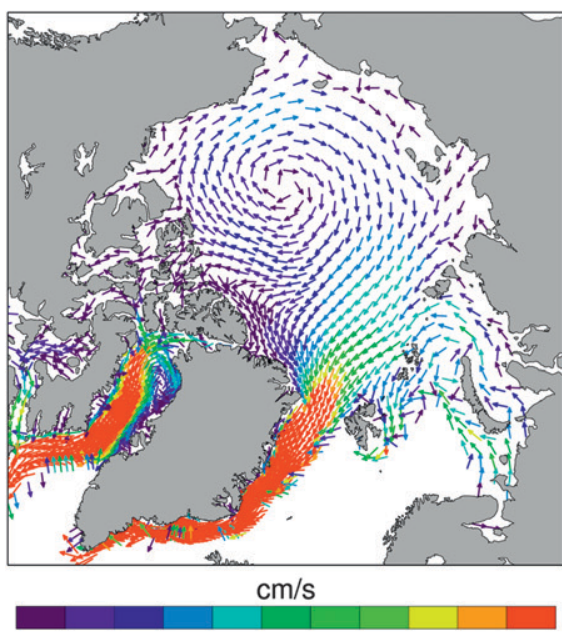

$\begin{array}{llllllllll}1 & 2 & 3 & 4 & 5 & 6 & 7 & 8 & 9 & 10\end{array}$

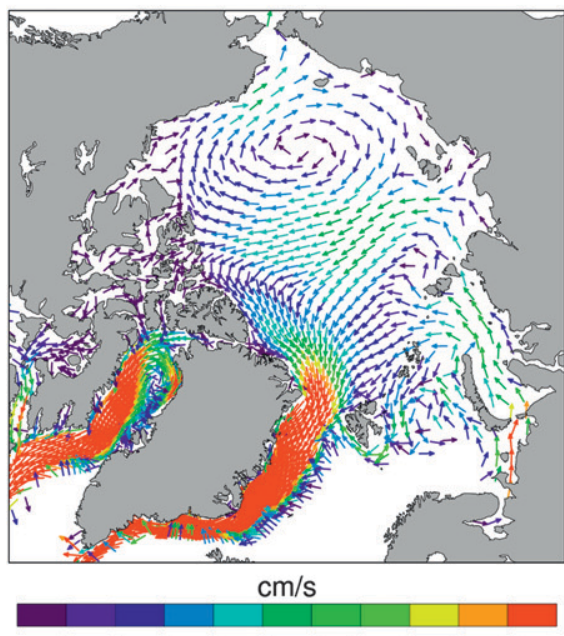

$\begin{array}{llllllllll}1 & 2 & 3 & 4 & 5 & 6 & 7 & 8 & 9 & 10\end{array}$

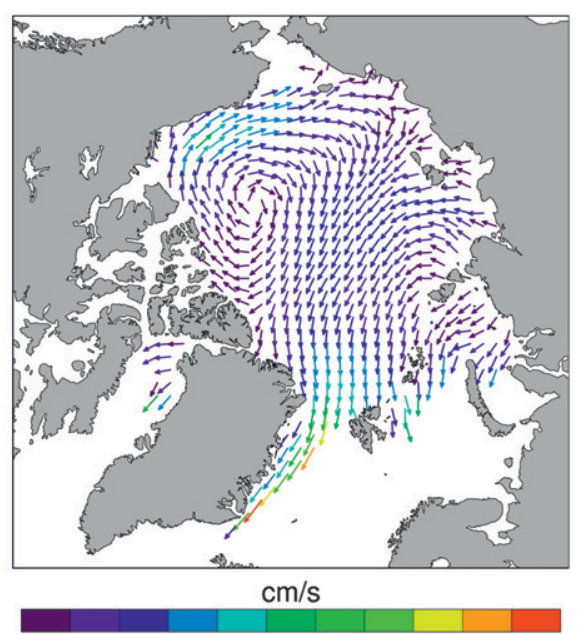

$\begin{array}{llllllllll}1 & 2 & 3 & 4 & 5 & 6 & 7 & 8 & 9 & 10\end{array}$

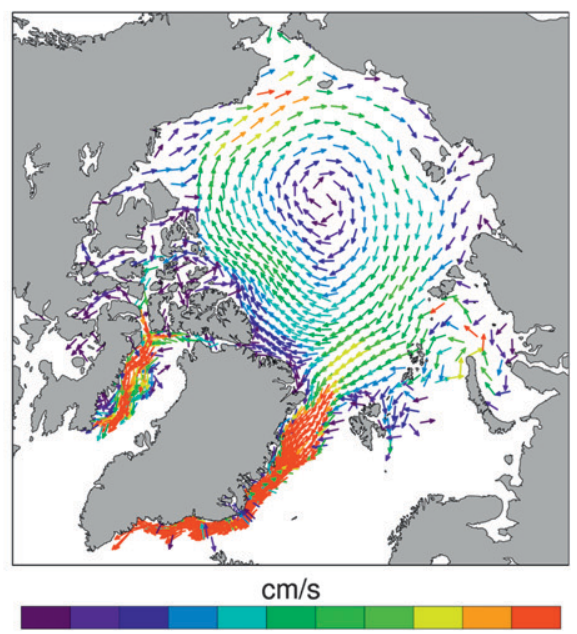

$\begin{array}{llllllllll}1 & 2 & 3 & 4 & 5 & 6 & 7 & 8 & 9 & 10\end{array}$

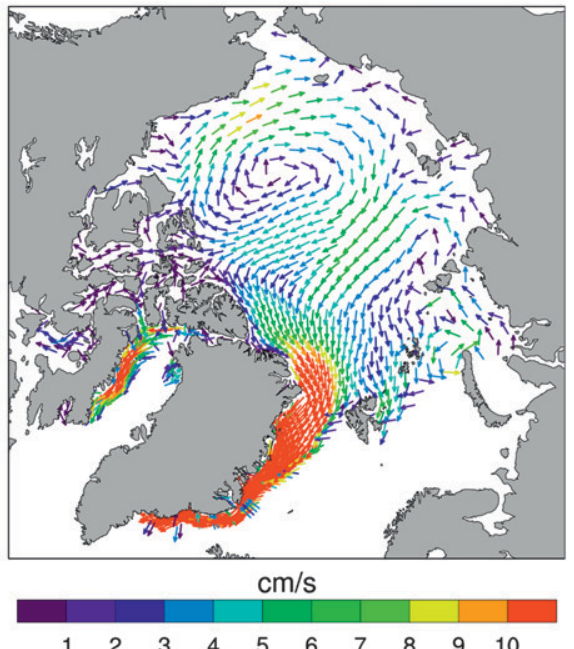

$\begin{array}{llllllllll}1 & 2 & 3 & 4 & 5 & 6 & 7 & 8 & 9 & 10\end{array}$

FIG. 10. Ice motion vectors for (left) March and (right) October for (top) Pathfinder project data, (middle) the ECHAM run, and (bottom) the FNCEP run. For Pathfinder data, every fifth vector is shown; for ECHAM and FNCEP runs, every second vector is shown. The speed of each vector is color coded $\left(\mathrm{cm} \mathrm{s}^{-1}\right)$. 

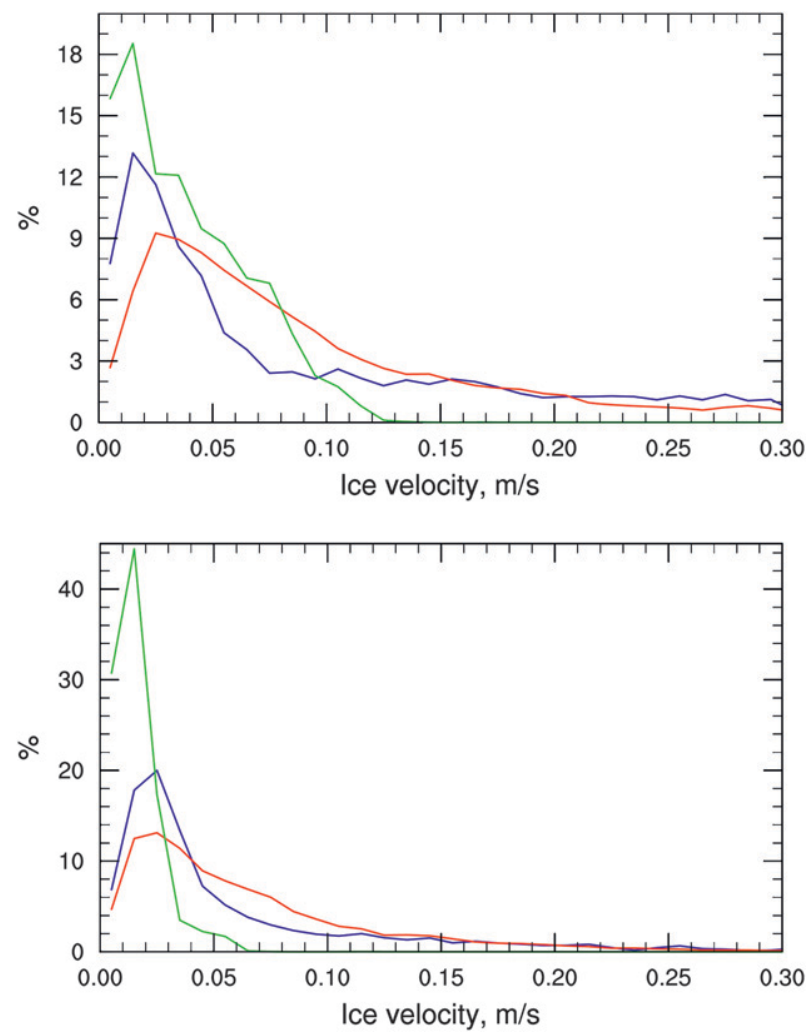

FIG. 11. Distribution of sea ice velocities from the entire Northern Hemisphere for (top) March and (bottom) September. Percentage values of the $y$ axis correspond to histogram bins along the $x$ axis with a bin width of $0.01 \mathrm{~m} \mathrm{~s}^{-1}$ beginning at 0.001 . Shown are Pathfinder data, the ECHAM run, and the FNCEP run as green, red, and blue curves, respectively. Note the different vertical scale on graphs.

Canadian Archipelago toward the Eurasian shelf, the coast of Alaska and the Fram Strait, and the position of the ECHAM $0^{\circ} \mathrm{C}$ isotherm essentially coincides with the NCEP-RA1 reanalysis. In contrast, the ECHAM September SAT distribution is centered around a minimum located near the geometric North Pole, while the minimum in the NCEP-RA1 reanalysis is shifted toward Greenland and on average is higher by $0.6^{\circ} \mathrm{C}$. With respect to SLP (which in the figure are superimposed on the SAT fields), the respective field for the ECHAM run indicates an anticyclonic atmospheric circulation system centered on the North Pole whereas in the NCEP-RA1 reanalysis a low pressure system spreads in a troughlike fashion from the Icelandic minimum up to the Laptev Sea.

To better highlight the differences between the two atmospheric forcing fields and to discuss their dynamical consequences for the coupled sea ice-ocean model, we show in Fig. 14 respective difference fields for SLP and SAT. The upper part of the figure reveals a pronounced quasi-permanent high pressure anomaly in the ECHAM run relative to the NCEP reanalysis, located over the

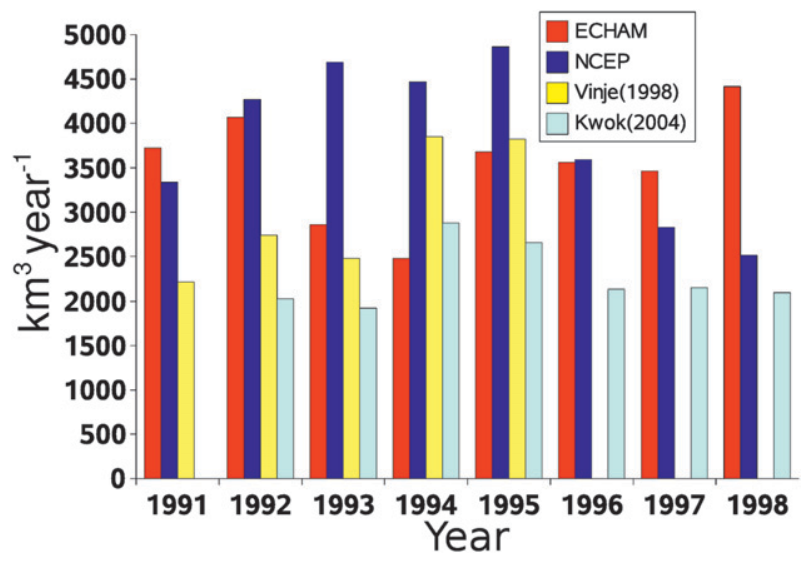

FIG. 12. Sea ice volume transport through the Fram Strait as simulated by the ECHAM and FNCEP model runs and analyzed by previous studies.

North Pole. This is especially obvious in September when the high pressure system forms a quasi-permanent anticyclonic atmospheric gyre that occupies large parts of the Arctic. The respective Ekman transport leads to an anomalous convergence of thick ice in the central Arctic in the ECHAM run during summer months, explaining why in the ECHAM run (and potentially in other IPCCtype models) too much sea ice is being found in the central Arctic Basin that is hardly varying in time. In general terms, SLP gradients are associated with surface wind stress fields, and SLP therefore affects the dynamical part of the ice model. Because of this, sea ice drift is nearly parallel to the isobars (Zubov and Somov 1940; Kwok 2008), and this holds also for the difference fields of SLP and differences in sea ice transports shown in the figure. In essence, Fig. 14 suggests that the error in the ECHAM atmosphere in form of an anticyclonic circulation around the geographic North Pole is driving a similar, but erroneous gyre in the sea ice, which in turn is responsible for the wrong sea ice distribution and sea ice thickness diagnosed above in the ECHAM run.

Nevertheless, errors arise also from the atmospheric thermal forcing of sea ice (lower row of Fig. 14). In March the ECHAM run are too warm to the north of Greenland, between Spitsbergen and the Novaya Zemlya Archipelago, and in the Baffin Bay and Labrador Sea, where the differences in SAT reach $7^{\circ} \mathrm{C}$; over most of the remaining parts of the Arctic Ocean differences are typically of the order of $1^{\circ}-2^{\circ} \mathrm{C}$. In the ECHAM run, temperature gradients over the Arctic seas are lower than in the NCEPRA1 reanalysis; also over large areas to the north of Greenland ECHAM is too warm. ECHAM is colder than the NCEP-RA1 reanalysis by up to $6^{\circ} \mathrm{C}$ in the Laptev Sea and the western part of the East Siberian Sea and over the Chukchi Sea. During September, the ECHAM SAT is lower than the NCEP-RA1 reanalysis over large parts of 

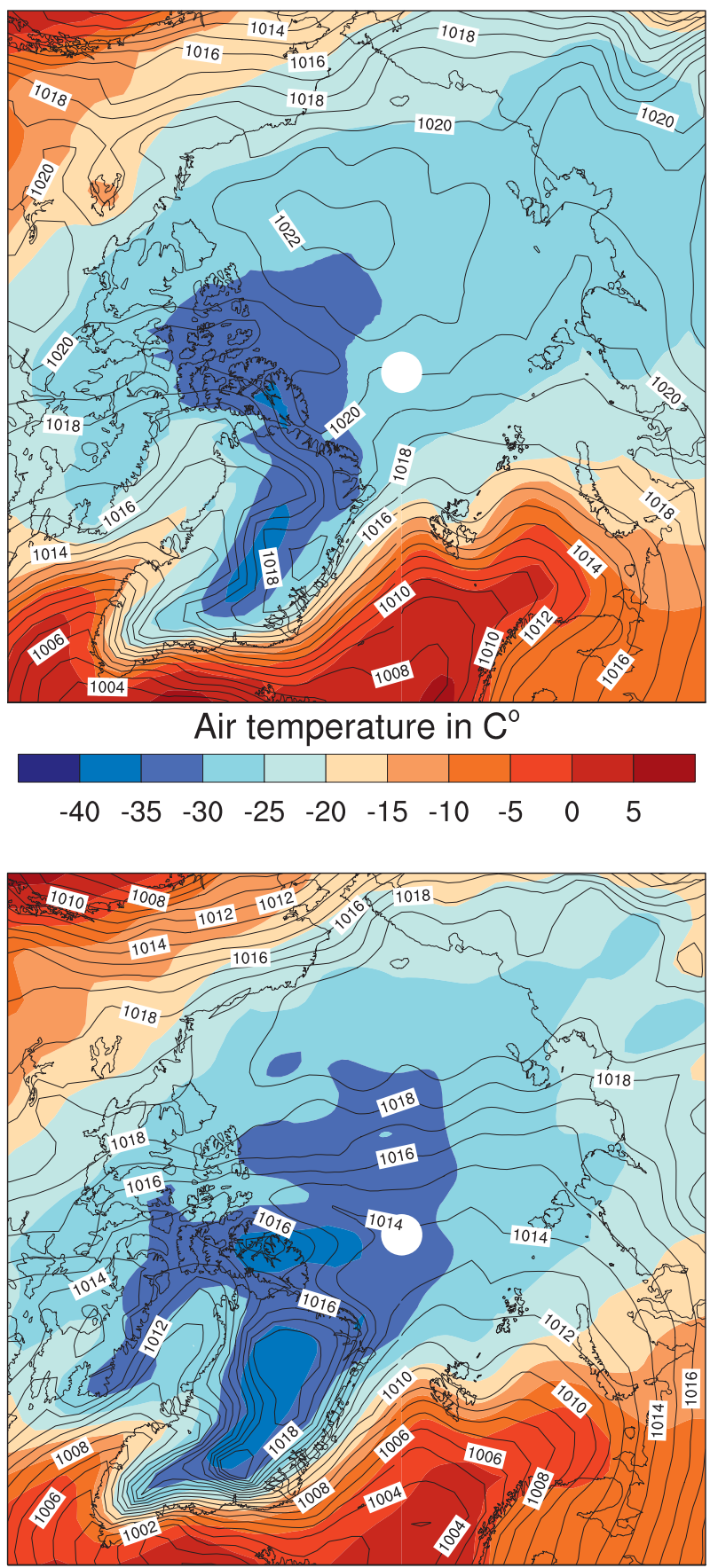

Air temperature in $\mathrm{C}^{\circ}$

$\begin{array}{llllllllll}-40 & -35 & -30 & -25 & -20 & -15 & -10 & -5 & 0 & 5\end{array}$
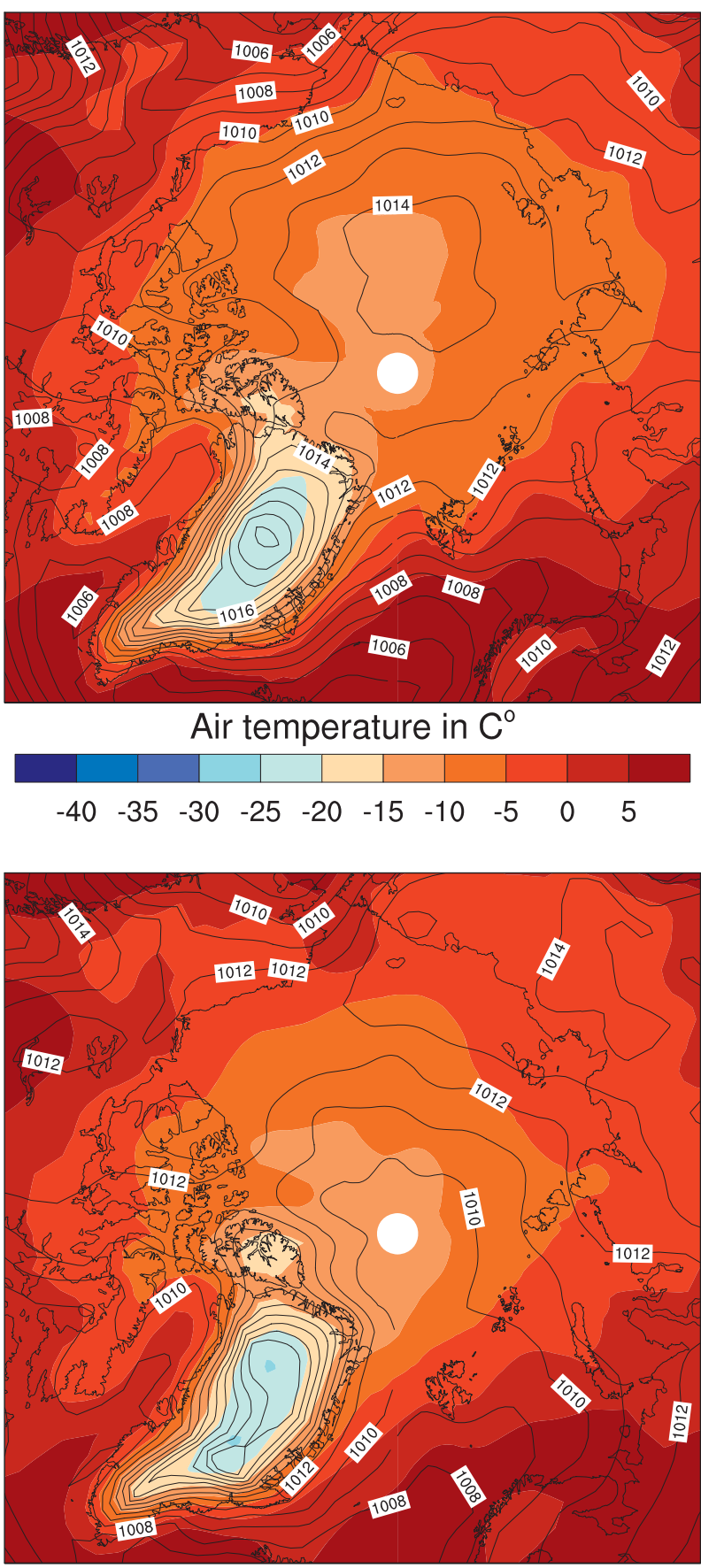

Air temperature in $\mathrm{C}^{\circ}$

$\begin{array}{llllllllll}-40 & -35 & -30 & -25 & -20 & -15 & -10 & -5 & 0 & 5\end{array}$

FIG. 13. Climatological monthly mean surface air temperature (contours, color coded, ${ }^{\circ} \mathrm{C}$ ) and sea level pressure (contours, hPa) fields for (left) March and (right) September. Shown are results for (top) ECHAM and (bottom) the NCEP-RA1 reanalysis.

the Arctic, except north of Greenland and over parts of the Canadian Archipelago where ECHAM is warmer, up to $3^{\circ} \mathrm{C}$ near Ellesmere Island. ECHAM is colder mainly over the Arctic Seas, up to $6^{\circ} \mathrm{C}$ over the Laptev Sea and the western part of the East Siberian Sea and over the Chukchi Sea.

Because SAT affects the thermodynamics of sea ice, the differences in SIC between the ECHAM and the 


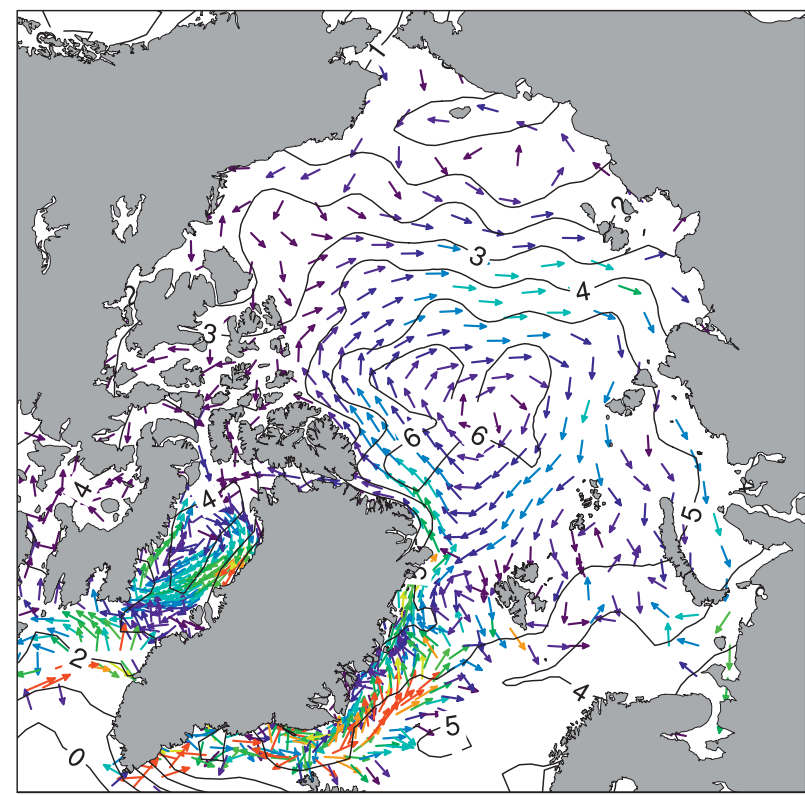

$\mathrm{cm} / \mathrm{s}$

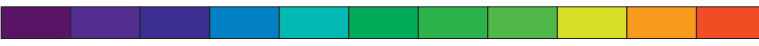

$\begin{array}{llllllllll}1 & 2 & 3 & 4 & 5 & 6 & 7 & 8 & 9 & 10\end{array}$

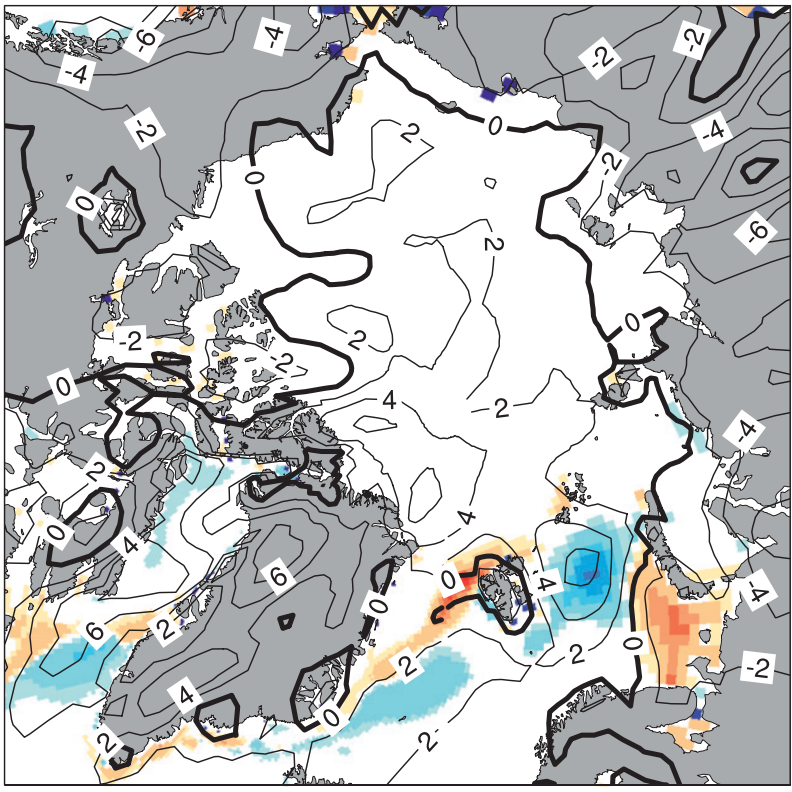

frac.

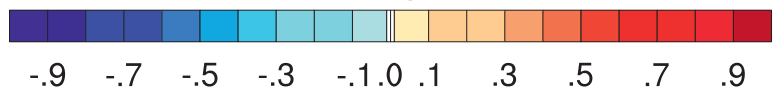

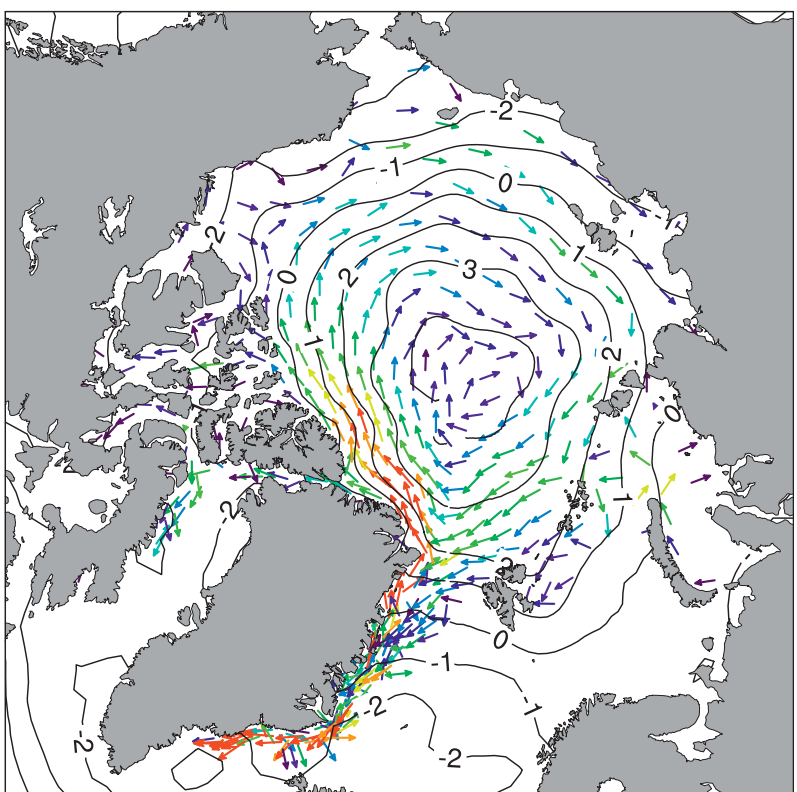

$\mathrm{cm} / \mathrm{s}$

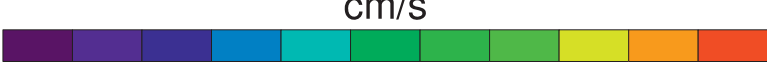

$\begin{array}{llllllllll}1 & 2 & 3 & 4 & 5 & 6 & 7 & 8 & 9 & 10\end{array}$

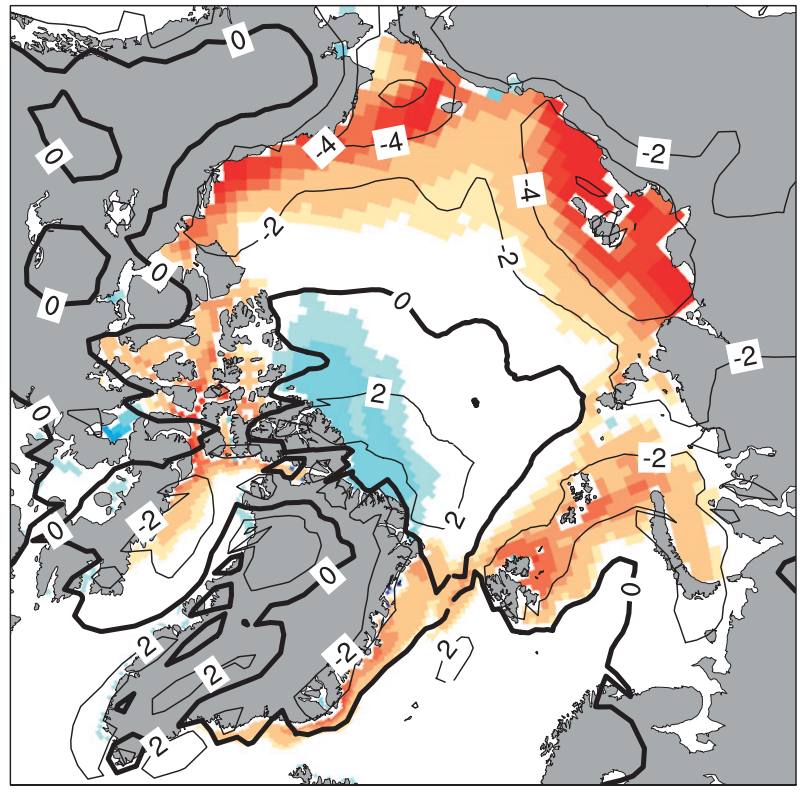

frac.

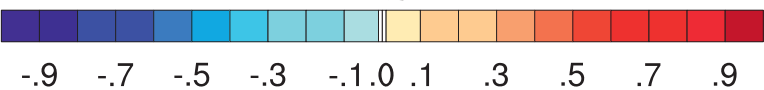

FIG. 14. (top) Differences between the climatological monthly mean (left) March and (right) September ECHAM-NCEP-RA1 SLP (contour interval is $1 \mathrm{hPa}$ ). Superimposed are the vectors of the respective climatological monthly mean difference fields for ice motions, with only every second vector plotted and speeds color coded in $\mathrm{cm} \mathrm{s}^{-1}$. (bottom) Contours show differences in climatological (left) March and (right) September ECHAM-NCEP-RA1 SAT fields. Superimposed in color are respective ECHAM-GSFC SIC difference fields. 
GSFC data are well correlated with the differences in SAT of ECHAM and the NCEP-RA1 reanalysis. In March, the area of the biggest SIC differences, located between Spitsbergen and the Novaya Zemlya Archipelago, coincides with the region of the biggest SAT error in ECHAM. During September, the too-large ECHAM SAT north of Greenland can help to explain the too-low ECHAM SIC there. Conversely, too-low ECHAM SAT over the Siberian seas, the Bering Strait, and the Canadian coast, associated with a shift of the Arctic gyre, may be partly responsible for too-high ECHAM SIC in these regions. There is a possibility that larger area of open water increase upward heat flux and cause SAT increase, but this process probably has a smaller impact in this case since SAT further south, over Siberia, are also too high in the ECHAM run.

While interpreting the results, one has to recall that the NCEP-RA1 SAT and SLP fields in the Arctic are far from perfect. The NCEP-RA1 was compared with observations from the "North Pole" drifting stations (NP) by Makshtas et al. (2007). The authors found that for the period of 1978-91 in the spring SAT from NCEP-RA1 is higher than observed (by $2.3^{\circ} \mathrm{C}$ ) at the NP, but in autumn it is lower (by $1.8^{\circ} \mathrm{C}$ ). SLP from NCEP-RA1 and NP showed good agreement between datasets in all periods, but NCEP-RA1 SLP in most cases was a bit lower than NP SLP. Taking into account these two parameters as well as a total cloudiness, specific humidity, and wind on $10 \mathrm{~m}$, the authors concluded that RA1 data should be used with "great caution" as forcing for sea ice models. Despite the uncertainties in the NCEP reanalysis, results of the ocean-ice model driven by the NCEP-RA1 reanalysis are nevertheless superior relative to ECHAM results and we can anticipate that with even better atmospheric forcing fields, the simulation of the coupled ocean-ice model would improve further. While interpreting the difference in atmospheric forcing between the two analyzed model runs one also has to recall that the NCEP run is performed in an uncoupled mode, while the ECHAM run is a coupled system. Clearly the comparison of two offline model runs would be ideal. However, the ECHAM5 atmosphere already "remembers" all feedbacks that it gets from the ocean during the coupled run. Although the surface fluxes (bulk formulas) in the FNCEP and ECHAM setups do differ, making an "offline" run with the ECHAM5 atmosphere from the coupled run would show only the sensitivity of the solution to the differences in the bulk formulas, and would not contribute to the scientific question addressed in the paper.

\section{b. Ocean forcing}

Similar to the atmospheric forcing, the ocean circulation can influence sea ice in two different ways: 1) dynamically, by affecting sea ice transport, and 2) thermodynamically, by sea ice melting and freezing. However, when analyzing ocean surface currents under the ice (not shown), one finds that in both simulations ocean currents essentially follow the main pathways of sea ice transport (accounting for the respective angle of rotation) and therefore do not force the ice velocity and direction. A more important ocean forcing mechanism might therefore be that Atlantic water entering from the Nordic seas through the Fram Strait and Barents Sea pushes under the cold fresh surface layer, leading to a relatively warm salty layer between 200- and 600-m depth named the Atlantic water (AW) layer. Although the temperature of the AW layer is higher than in water masses above and below, the heat exchange with the surface layer is suppressed by the cold halocline layer (CHL) separating both water masses. The correct simulation of these two important features of the Arctic Ocean (AW and CHL) is important for simulating the correct water-mass properties of the upper Arctic Ocean, yet it remains a challenge, even in regional models. According to Holloway et al. (2007), models participating in the AOMIP tend to overestimate the AW layer thickness and exhibited thermally stratified upper ocean; that is, they failed to form a proper CHL. This shortcoming can have a pronounced impact on the heat budget of the upper Arctic Ocean layer and will affect sea ice on decadal to centennial time scales (Steele and Boyd 1998; Martinson and Steele 2001).

To test the vertical thermal and haline stratification of the ECHAM and FNCEP runs, we compare temperature, salinity, and density vertical profiles with the Polar Science Center Hydrographic Climatology (PHC 3.0; Steele et al. 2001) in the Eurasian sector of the Arctic Ocean, where temperature of AW is highest (Fig. 15). Both runs show thicker, shallower and warmer AW layers. The ECHAM run shows a rapid temperature increase right from the surface without any indication of the mixedlayer presence. In the FNCEP run, the mixed layer is disturbed by a warmer spike in the middle, probably because of the temperature restoring process at the surface. We note that a mixed layer is lacking in all salinity profiles and a strong pycnocline starts right from the surface in the two simulations, closely following the observed salinity profile. We also note that the Brunt-Väisälä frequency (BVF; not shown) is quite similar among the datasets in the first $50 \mathrm{~m}$ of the water column, but in the range of 50-150 $\mathrm{m}$ the BVF is considerably smaller in the FNCEP run than in the PHC climatology and the ECHAM run.

We see from Fig. 15 that the heat content of the Arctic Ocean is quite different between the two runs and between the model simulations and the observations. To test if this does affect sea ice budget and sea ice 

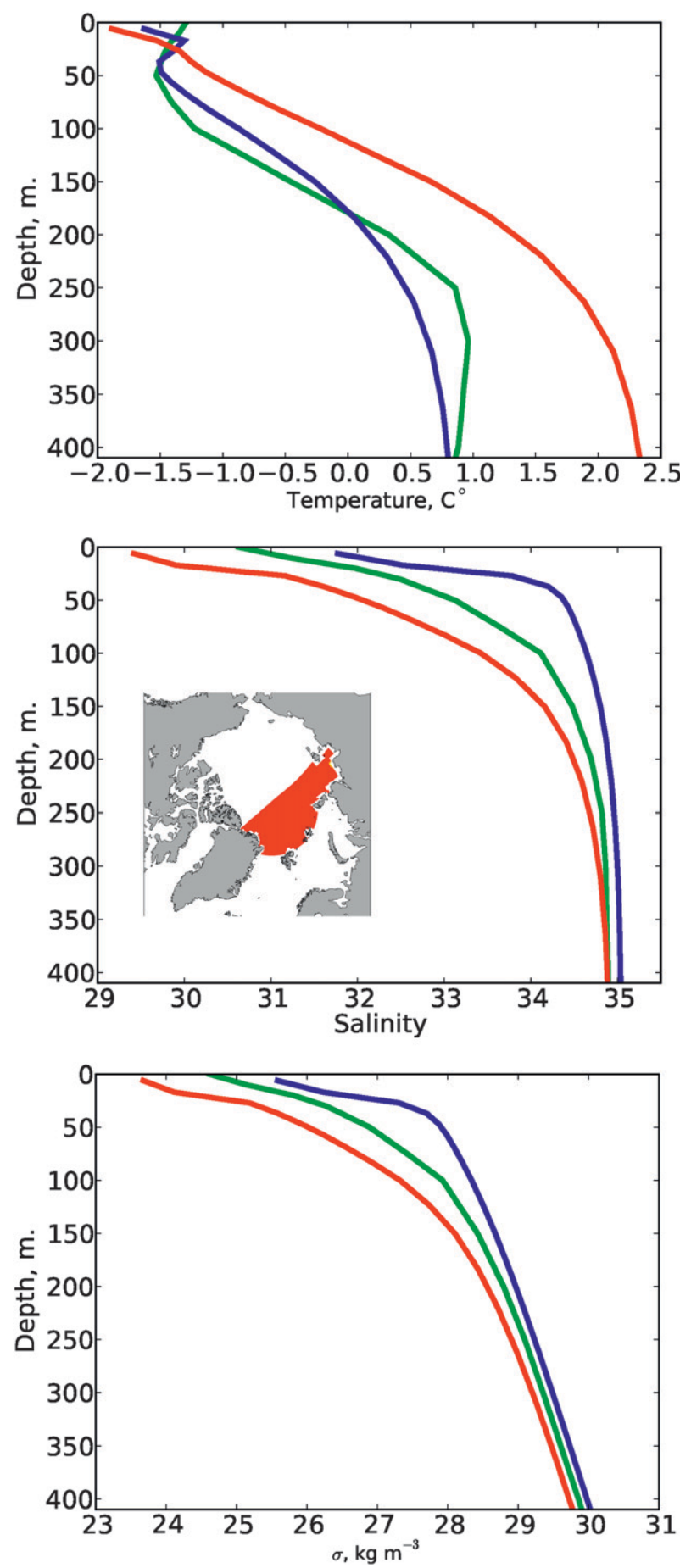

FIG. 15. (top) Vertical profiles of September ocean, top: temperature, middle: salinity, and bottom: density from PHC climatology and model runs (1980-99). Green: PHC, red: ECHAM run, and blue: FNCEP run. (middle) Parameters are averaged over the area shown in the middle panel. distribution in the model simulations, we analyze the heat convergence in the model's Arctic Ocean and the associated heat loss to the ice or atmosphere. To do so, we compute the total top to bottom heat content change and heat convergence in area 1 (Laptev Sea; see Fig. 15 for the area) where heat changes are largest in both runs. While doing the computations, we assume that lateral diffusion is negligible (or at least the same between the two runs) and that differences in heat content change and heat convergence will serve as a diagnostic of heat exchange through the surface of the ocean (either to sea ice or the atmosphere).

Results are shown in the top row of Fig. 16 in terms of area-averaged mean September SIC and surface heat exchange in ECHAM and FNCEP runs. Positive values indicate an oceanic heat uptake through the surface. In both runs curves are visually anticorrelated with each other (a formal correlation coefficient for ECHAM is -0.18 , for the FNCEP run -0.19), showing a decrease of ocean heat uptake through the surface, or increase in heat loss to the atmosphere simultaneous to an increase of SIC and vice versa. This suggests that the ocean heat content is not used to first order to melt sea ice; rather, during periods with increased amounts of open water, the ocean tends to gain heat from the atmosphere (by absorbing heat through the surface), and during years with high SIC the ocean tends to lose the heat to the atmosphere and/or to sea ice. A noticeable exception from this tendency can be found during the year 1991, when in the FNCEP run we see a spike in heat loss from the ocean associated with close to zero SIC in the Laptev Sea, simultaneous to high lateral heat convergence and increase in total heat content caused by the advection from aside (Fig. 16, bottom). We also note that the increase in ocean heat content occurs after SIC declines, not before. In contrast, two events of increased heat content (by advective heat inflow) in the ECHAM run are not associated with any change in the SIC record (Fig. 16, bottom).

In summary, we conclude that in both model runs, heat from the ocean might influence SIC only during extreme events of strong lateral influx of heat, and even then a relation between regional heat content increase and sea ice melting is not unambiguous. We note, however, that on time scales longer than those considered here, the impact of ocean heat content on the development of SIC remains to be expected.

\section{Discussion and conclusions}

This paper provides a contribution to a detailed evaluation of IPCC-type coupled climate models against observations with focus on the Arctic sea ice system. The 

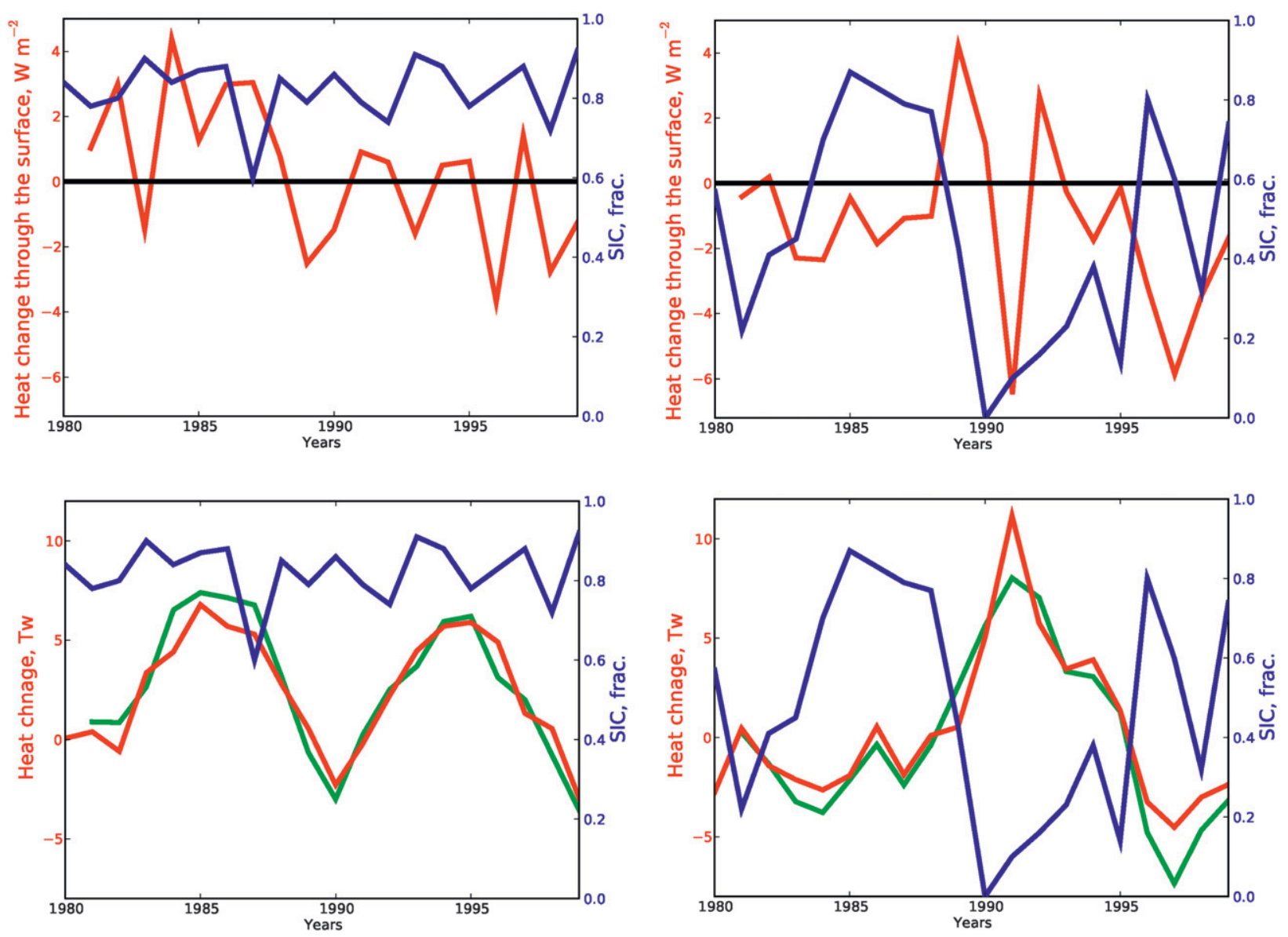

FIG. 16. (top) Heat change through the surface (red) and September SIC (blue). (bottom) Heat convergence (red), total heat content change (green), and September SIC (blue). (left) ECHAM run, (right) FNCEP run.

IPCC projections tend to be interpreted as forecasts of the Arctic sea ice system. However, Eisenman et al. (2007) provided already a critique of the limited skill ice forecasting models generally. The authors concluded that IPCC-type models during AR4 simulated satisfactorily the present-day sea ice conditions, but that uncertainties in the atmospheric cloud cover combined with a high sensitivity of equilibrium sea ice thickness to sea ice albedo lead to high uncertainties in sea ice predictions. Here we demonstrate that even for present-day conditions sea ice simulations by IPCC-type models show large uncertainties. Although our in depths analysis shows shortcomings of one model, the model was deemed one of the best in simulating sea ice characteristics; Parkinson et al. (2006) compared the seasonal cycle in satellite SIE with respective results from 11 models participating in the IPCC Fourth Assessment Report and reported that the ECHAM/MPI-OM model was among the most favorable models to represent the annual cycle of sea ice in the Northern Hemisphere. We can therefore expect that results reported here from the ECHAM run should be representative for other IPCC-type models as well and that problems found in our own analysis and summarized above might actually apply to many other climate models. By scrutinizing our own model, we attempt to identify possible sources of errors that need to be improved to improve the skill of present-day Arctic system climate simulations and projections of the Arctic system into the next century.

From a comparison of two runs of the identical MPI-M ocean-ice model [one forced by an interactive atmosphere (ECHAM run), the other forced by the quasirealistic NCEP-RA1 reanalysis surface fluxes (FNCEP run)] against simultaneous observations of sea ice characteristics during the period 1980-99, we can draw several main conclusions. Some confirming conclusions have been drawn by previous studies, and it can be expected that the shortcomings documented here apply more generally to IPCC-type coupled climate models.

- While simulated wintertime sea ice distributions are close to what has been observed, the summer sea ice 
conditions are highly sensitive to details of the atmospheric forcing. Simulations by the fully coupled IPCC-type ECHAM model cause significant deficits in essentially all present-day ice parameters over the Arctic Ocean. In contrast, summer sea ice results are much more realistic in the NCEP-driven run, which provides quasi-realistic present day atmospheric conditions.

- A major agent for deficits in the sea ice conditions, including uncertainties in basin-scale sea ice transports, is an unrealistic high pressure system in the ECHAM run centered to the geometric North Pole in the model, which occupies the entire central Arctic. It drives a quasi-permanent anticyclonic basin-scale gyre of ice transport and causes, through an Ekman ice drift, the buildup of thick ice in the Central Basin. Errors in the associated surface wind stress (atmospheric circulation) leading to errors in the sea ice pathways and dynamics are a primary reason for the errors in the ECHAM sea ice.

- The ECHAM run substantially underestimates the atmospheric interannual and decadal variability over the Arctic. Accordingly the interannual to decadal variability of sea ice cover and sea ice transport is underrepresented in the ECHAM run, which in the FNCEP run is significantly correlated with the NAO/ AO index.

- Sea ice transports are higher in amplitude in both model runs than in Pathfinder data, and ice transport patterns in the model simulations do not coincide with the patterns in the Pathfinder data, especially in the ECHAM run. Associated higher ice velocities lead to an unrealistically high ice export through the Fram Strait in the model simulations; differences in the sea ice advection pathways from both runs feed sea ice to the Fram Strait from different source regions, which affect the thickness and thus the ice volume leaving the Arctic toward the Nordic seas.

- While hydrographic conditions are quite different between the two analyzed runs, we find no indications of a substantial impact of the ocean heat content differences on the sea ice distribution or variation on interannual to decadal time scales-again pointing toward the atmosphere as the dominant driver for Arctic sea ice variability, with the ocean on basin-scale responding more passively in its air-sea interaction to varying insulation through sea ice coverage. The situation might be quite different on centennial time scales, however, pointing toward uncertainties of IPCC sea ice projections to also originate from the ocean. This means that a good representation of the ocean circulation and its temporal variability-changes is critical for simulations of present and future ice-ocean interactions (cf. also Bitz et al. 2006).
- The uncertainties in the ECHAM atmosphere also lead to substantial differences of the Arctic Ocean circulation, its hydrography, and its water masses. In particular, the subsurface ECHAM Arctic Ocean is too warm by several degrees Celsius. However, a strong near-surface halocline prevents this warm water from melting the sea ice from underneath. The halocline structure in the FNCEP run is much more similar with observed conditions, but weaker, and temperatures in the ocean interior are higher. This may lead to penetration of heat through the halocline to the ice bottom in the FNCEP run. However, not enough in situ observations exist to evaluate the simulated ocean circulation comprehensively.

This study is the first examination of the ECHAM/ MPI-OM model sea ice characteristics and is an attempt to understand the causes for discrepancies between model and observations when both atmosphere and ocean forcing were considered. For the first time, we also compare simulated thickness of the sea ice against datasets that have reliable information about the thickness in the Arctic seas, were it to play a crucial role during summer melting season. We show that not only the wrong SLP field but also lack of interannual atmospheric variability is an important cause for the difficulties in proper Arctic sea ice simulations.

We conclude that in order to improve the present-day simulations of the Arctic sea ice system, the ECHAM atmosphere needs to be improved over the Arctic in both its time-mean and time-varying components. Our findings are in line with conclusions drawn previously by Hunke and Holland (2007) who, from a comparison of the simulation of sea ice over the Arctic using three different atmospheric forcing datasets, also noted the fundamental impact of the atmospheric forcing on the thickness simulations as well as significantly different advection of heat and salt and ice-ocean stress. We identify here a quasi-permanent Arctic atmospheric circulation as the primary reason for the deficits in the simulated sea ice parameters.

Causes for this artificial atmospheric circulation around the model's North Pole are unknown at this point and need a serious model improvement effort to remedy. Also unknown is the cause for the lack of Arctic variability in the ECHAM model as well as the extent to which problems in the simulation of the summer sea ice jointly with the underestimation of atmospheric variability affect the quality of sea ice projections over the next century by the ECHAM model and needs further investigations. The same holds for the extensive warm bias in the simulated Arctic Ocean and its impact on climate projections, for example, by melting sea ice from below. 
Acknowledgments. We thank H. Haak and J. Jungclaus from MPI-M for making the model results available and for many helpful discussions. We thank also Carl Wunsch for helpful comments. Two anonymous reviewers helped improve the paper significantly. All model simulations are made in Deutsches Klimarechenzentrum (DKRZ). This project was funded, in part, through a grant from the Max Planck Society. This is a contribution to the CLISAP Climate Initiative of the KlimaCampus Hamburg.

\section{REFERENCES}

Arzel, O., T. Fichefet, and H. Goosse, 2006: Sea ice evolution over the 20th and 21st centuries as simulated by current AOGCMs. Ocean Modell., 12, 401-415.

Bitz, C. M., J. C. Fyfe, and G. M. Flato, 2002: Sea ice response to wind forcing from AMIP models. J. Climate, 15, 522-536.

— , P. R. Gent, R. A. Woodgate, M. M. Holland, and R. Lindsay, 2006: The influence of sea ice on ocean heat uptake in response to increasing $\mathrm{CO}_{2}$. J. Climate, 19, 2437-2450.

Bourke, R. H., and R. P. Garrett, 1987: Sea ice thickness distribution in the Arctic Ocean. Cold Reg. Sci. Technol., 13, 259-280.

Cassano, J. J., P. Uotila, and A. Lynch, 2006: Changes in synoptic weather patterns in the polar regions in the twentieth and twenty-first centuries, part 1: Arctic. Int. J. Climatol., 26, 10271049.

Cavalieri, D., C. Parkinson, P. Gloersen, and H. J. Zwally, 1996, updated 2008: Sea ice concentrations from Nimbus-7 SMMR and DMSP SSM/I passive microwave data 1980-1999. National Snow and Ice Data Center, digital media. [Available online at http://nsidc.org/data/nsidc-0051.html.]

Chapman, W. L., and J. E. Walsh, 2007: Simulations of Arctic temperature and pressure by global coupled models. J. Climate, 20, 609-632.

Comiso, J. C., D. J. Cavalieri, C. L. Parkinson, and P. Gloersen, 1997: Passive microwave algorithms for sea ice concentration: A comparison of two techniques. Remote Sens. Environ., 60, 357-384.

Deweaver, E., and C. M. Bitz, 2006: Atmospheric circulation and its effect on Arctic sea ice in CCSM3 simulations at medium and high resolution. J. Climate, 19, 2415-2436.

Eisenman, I., N. Untersteiner, and J. S. Wettlaufer, 2007: On the reliability of simulated Arctic sea ice in global climate models. Geophys. Res. Lett., 34, L10501, doi:10.1029/2007GL029914.

Flato, G. M., and Coauthors, 2004: Sea-ice and its response to $\mathrm{CO}_{2}$ forcing as simulated by global climate models. Climate Dyn., 23, 229-241.

Fowler, C., 2003 (updated 2007): Polar Pathfinder daily $25 \mathrm{~km}$ EASE-grid sea ice motion vectors. National Snow and Ice Data Center, digital media. [Available online at http://nsidc. org/data/nsidc-0116.html.]

Gent, P. R., J. Willebrand, T. J. McDougall, and J. C. McWilliams, 1995: Parameterizing eddy-induced tracer transports in ocean circulation models. J. Phys. Oceanogr., 25, 463-474.

Gerdes, R., and C. Köberle, 2007: Comparison of Arctic sea ice thickness variability in IPCC climate of the 20th century experiments and in ocean-sea ice hindcasts. J. Geophys. Res., 112, C04S13, doi:10.1029/2006JC003616.

Griffies, S. M., 1998: The Gent-McWilliams skew flux. J. Phys. Oceanogr., 28, 831-841.
Haak, H., 2004: Simulation of low-frequency climate variability in the North Atlantic Ocean and the Arctic. Ph.D. thesis, University of Hamburg, 115 pp.

_ J. Jungclaus, U. Mikolajewicz, and M. Latif, 2003: Formation and propagation of great salinity anomalies. Geophys. Res. Lett., 30, 1473, doi:10.1029/2003GL017065.

Hagemann, S., and L. Dümenil, 1997: A parametrization of the lateral waterflow for the global scale. Climate Dyn., 14, 17-31.

— terization scheme for climate models by the use of high resolution data derived from satellite observations. Climate Dyn., 21, 349-359.

Hibler, W. D., 1979: Dynamic thermodynamic sea ice model. J. Phys. Oceanogr., 9, 815-846.

Holloway, G., and Coauthors, 2007: Water properties and circulation in Arctic Ocean models. J. Geophys. Res., 112, C04S03, doi:10.1029/2006JC003642.

Hu, Z.-Z., S. I. Kuzmina, L. Bengtsson, and D. M. Holland, 2004: Sea-ice change and its connection with climate change in the Arctic in CMIP2 simulations. J. Geophys. Res., 109, D10106, doi:10.1029/2003JD004454.

Hunke, E. C., and M. M. Holland, 2007: Global atmospheric forcing data for Arctic ice-ocean modeling. J. Geophys. Res., 112, C04S14, doi:10.1029/2006JC003640.

Johnson, M., S. Gaffigan, E. Hunke, and R. Gerdes, 2007: A comparison of Arctic Ocean sea ice concentration among the coordinated AOMIP model experiments. J. Geophys. Res., 112, C04S11, doi:10.1029/2006JC003690.

Jungclaus, J. H., and Coauthors, 2006: Ocean circulation and tropical variability in the coupled model ECHAM5/MPI-OM. J. Climate, 19, 3952-3972.

Kalnay, E., and Coauthors, 1996: The NCEP/NCAR 40-Year Reanalysis Project. Bull. Amer. Meteor. Soc., 77, 437-471.

Kattsov, V., G. Alekseev, T. Pavlova, P. Sporyshev, R. Bekryaev, and V. Govorkova, 2007: Modeling the evolution of the world ocean ice cover in the 20th and 21st centuries. Izv. Atmos. Ocean. Phys., 43, 142-157.

Kauker, F., T. Kaminski, M. Karcher, R. Giering, R. Gerdes, and M. Voßbeck, 2009: Adjoint analysis of the 2007 all time arctic sea-ice minimum. Geophys. Res. Lett., 36, L03707, doi:10.1029/ 2008 GL036323.

Konstantinov, Y. B., and K. I. Grachev, 2000: High-Latitude Airborne Expeditions Sever (1937, 1941-1993) (in Russian). Gidrometeoizdat Publishing House, $176 \mathrm{pp}$.

Kwok, R., 2008: Summer sea ice motion from the $18 \mathrm{GHz}$ channel of AMSR-E and the exchange of sea ice between the Pacific and Atlantic sectors. Geophys. Res. Lett., 35, L03504, doi:10.1029/ 2007 GL032692.

_ A. Schweiger, D. A. Rothrock, S. Pang, and C. Kottmeier, 1998: Sea ice motion from satellite passive microwave imagery assessed with ERS SAR and buoy motions. J. Geophys. Res., 103C, 8191-8214.

—, G. F. Cunningham, and S. S. Pang, 2004: Fram Strait sea ice outflow. J. Geophys. Res., 109, C01009, doi:10.1029/ 2003JC001785.

Levitus, S., and Coauthors, 1998: NOAA Atlas NESDIS 18, World Ocean Database 1998: Volume 1: Introduction. U.S. Government Printing Office, 346 pp.

Lindsay, R. W., J. Zhang, A. Schweiger, M. Steele, and H. Stern, 2009: Arctic sea ice retreat in 2007 follows thinning trend. J. Climate, 22, 165-176.

Makshtas, A., D. Atkinson, M. Kulakov, S. Shutilin, R. Krishfield, and A. Proshutinsky, 2007: Atmospheric forcing validation for 
modeling the central Arctic. Geophys. Res. Lett., 34, L20706, doi:10.1029/2007GL031378.

Marsland, S. J., H. Haak, J. H. Jungclaus, M. Latif, and F. Roske, 2003: The Max-Planck-Institute global ocean/sea ice model with orthogonal curvilinear coordinates. Ocean Modell., 5, 91-127.

Martin, T., and R. Gerdes, 2007: Sea ice drift variability in Arctic Ocean Model Intercomparison Project models and observations. J. Geophys. Res., 112, C04S10, doi:10.1029/2006JC003617.

Martinson, D. G., and M. Steele, 2001: Future of the Arctic sea ice cover: Implications of an Antarctic analog. Geophys. Res. Lett., 28, 307-310.

Maslanik, J. A., M. C. Serreze, and R. G. Barry, 1996: Recent decreases in Arctic summer ice cover and linkages to atmospheric circulation anomalies. Geophys. Res. Lett., 23, 1677-1680.

Meier, W. N., 2005: Comparison of passive microwave ice concentration algorithm retrievals with AVHRR imagery in Arctic peripheral seas. IEEE Trans. Geosci. Remote Sens., 43, 1324-1337, doi:10.1109/TGRS.2005.846151.

Oberhuber, J. M., 1993: Simulation of the Atlantic circulation with a coupled sea ice-mixed layer-isopycnal general circulation model. Part I: Model description. J. Phys. Oceanogr., 23, 808-829.

Parkinson, C. L., and D. J. Cavalieri, 2008: Arctic sea ice variability and trends, 1979-2006. J. Geophys. Res., 113, C07003, doi:10.1029/2007JC004564.

_ - K. Y. Vinnikov, and D. J. Cavalieri, 2006: Evaluation of the simulation of the annual cycle of Arctic and Antarctic sea ice coverages by 11 major global climate models. J. Geophys. Res., 111, C07012, doi:10.1029/2005JC003408.

Pinto, J., S. Zacharias, A. Fink, G. Leckebusch, and U. Ulbrich, 2008: Factors contributing to the development of extreme North Atlantic cyclones and their relationship with the NAO. Climate Dyn., 32, 711-737, doi:10.1007/s00382-008-0396-4.

Polyakov, I. V., and Coauthors, 2003: Long-term ice variability in Arctic marginal seas. J. Climate, 16, 2078-2085.

Proshutinsky, A., and Z. Kowalik, 2007: Preface to special section on Arctic Ocean Model Intercomparison Project (AOMIP) studies and results. J. Geophys. Res., 112, C04S01, doi:10.1029/ 2006JC004017.

Redi, M. H., 1982: Oceanic isopycnal mixing by coordinate rotation. J. Phys. Oceanogr., 12, 1154-1158.

Roeckner, E., and Coauthors, 2003: The atmospheric general circulation model ECHAM 5. Part I: Model description. MPI-M Tech. Rep. 349, MPI-M, 127 pp.
Romanov, I. P., 1995: Atlas of Ice and Snow of the Arctic Basin and Siberian Shelf Seas. 2nd ed. Backbone Publishing Company, 277 pp.

Rothrock, D. A., D. B. Percival, and M. Wensnahan, 2008: The decline in Arctic sea-ice thickness: Separating the spatial, annual, and interannual variability in a quarter century of submarine data. J. Geophys. Res., 113, C05003, doi:10.1029/2007JC004252.

Semtner, A. J., 1976: A model for the thermodynamic growth of sea ice in numerical investigations of climate. J. Phys. Oceanogr., 6, 379-389.

Serreze, M. C., M. M. Holland, and J. Stroeve, 2007: Perspectives on the Arctic's shrinking sea-ice cover. Science, 315, 15331536.

Steele, M., and T. Boyd, 1998: Retreat of the cold halocline layer in the Arctic Ocean. J. Geophys. Res., 103 (C5), 10 41910435 .

— , R. Morley, and W. Ermold, 2001: PHC: A global ocean hydrography with a high-quality Arctic Ocean. J. Climate, 14, 2079-2087.

Stössel, A., and W. B. Owens, 1992: The Hamburg sea-ice model. Tech. Rep. 3, German Climate Computer Center (DKRZ), $61 \mathrm{pp}$.

Stroeve, J., M. M. Holland, W. Meier, T. Scambos, and M. Serreze, 2007: Arctic sea ice decline: Faster than forecast. Geophys. Res. Lett., 34, L09501, doi:10.1029/2007GL029703.

Valcke, S., A. Caubel, D. Declat, and L. Terray, 2003: OASIS Ocean Atmosphere Sea Ice Soil users guide. Tech. Rep., Centre Européen de Recherche et de Formation Avancée en Calcul Scientifique, $85 \mathrm{pp}$.

Vinje, T., N. Nordlund, A. Kvambekk, 1998: Monitoring ice thickness in Fram Strait. J. Geophys. Res., 103 (C5), $10437-$ 10449.

Walsh, J. E., and R. G. Crane, 1992: A comparison of GCM simulations of Arctic climate. Geophys. Res. Lett., 19, 29-32.

Zhang, J., R. Lindsay, M. Steele, and A. Schweiger, 2008: What drove the dramatic retreat of arctic sea ice during summer 2007 ? Geophys. Res. Lett., 35, L11505, doi:10.1029/2008GL034005.

Zhang, X., and J. E. Walsh, 2006: Toward a seasonally ice-covered Arctic Ocean: Scenarios from the IPCC AR4 model simulations. J. Climate, 19, 1730-1747.

Zubov, N. N., and M. M. Somov, 1940: Ice drift in the northern Arctic Basin (in Russian). Probl. Arct., 2, 51-68. 